\title{
Synthetic Credit Ratings and the Inefficiency of Agency Ratings
}

\author{
Doron Nissim* \\ Columbia Business School
}

July 2017

\begin{abstract}
This study develops and evaluates a model that generates synthetic credit ratings using accounting and market based information. The model performs very well in explaining agency ratings, suggesting that fitted values for unrated companies are likely to be reasonably precise. In addition, the synthetic credit ratings help explain cross sectional differences in CDS spreads, even after controlling for contemporaneous agency ratings. The incremental information provided by agency ratings relative to the synthetic ratings has declined substantially in recent years, possibly due to new SEC regulation that limits rating agencies' ability to obtain confidential information from rated companies. Consistent with the finding that agency ratings do not fully impound the information in the synthetic credit ratings, differences between the synthetic and agency ratings predict changes in agency ratings in subsequent months, especially for small companies. This relationship is very significant, both statistically and economically, and while it monotonically declines over the forecasting horizon, the difference between the synthetic and agency ratings predicts changes in agency ratings as far as 24 months later. There is no evidence of substantial improvement over the last thirty years in the timeliness of agency ratings with respect to the information in synthetic ratings. Investors, in contrast, appear to process the synthetic rating information in a timely fashion, as the difference between the synthetic and agency ratings does not predict changes in CDS spreads or in stock prices.
\end{abstract}

JEL Classification: G12, G14, G24, G28, G32, M41

Keywords: Credit ratings, rating agencies, credit risk, CDS, financial statement analysis, market efficiency

*604 Uris Hall, Columbia Business School, New York, NY 10027; dn75@columbia.edu.

Helpful comments were provided by Trevor Harris, Urooj Kahn, Stephen Penman, and participants in the Accounting Research Conference at Penn State University. 


\section{Introduction}

Credit ratings are used by investors, financial intermediaries, regulators, and other market participants. ${ }^{1}$ For example, debt investors and lenders use credit ratings in providing, pricing, and monitoring credit; lessors use credit ratings in lease negotiations; suppliers, employees, customers, and other operating counterparties use credit ratings in deciding whether and at what terms to transact with the company; and equity investors and financial officers use credit ratings in estimating the cost of debt capital (e.g., for WACC calculations), in valuing fixed claims (e.g., operating leases), and in estimating the probability of survival (e.g., to undo the bias in going concern DCF valuations). Credit ratings have additional effects besides providing information to various market participants. For example, many institutional investors (e.g., pension trusts, banks, insurance companies, broker-dealers) are (or were) restricted to investing in investment grade bonds (BBB- or higher), and bond and loan covenants often stipulate that the interest rate increases, or other terms of the debt change adversely, if the rating falls below a specified level (e.g., Manso, Strulovici and Tchistyi, 2010). While widely used when available, credit ratings are unavailable for most public companies.

This study generates synthetic credit ratings, estimated using accounting and market based proxies for determinants of credit quality (e.g., firm profitability, leverage, volatility) and the empirical relationship between those determinants and the credit ratings of rated companies. The approach involves several modifications compared to previous studies, primarily in specifying the conditioning variables. The model R-squared is high in each of the 374 sample months, and the estimated coefficients have the expected signs and are highly significant, both statistically and

\footnotetext{
${ }^{1}$ See, for example, Katz (1974), Pinches and Singelton (1978), Holthausen and Leftwich (1986), Jorion, Liu and Shi (2005), and Kisgen and Strahan (2010).
} 
economically. The coefficients are generally stable over the sample period, except that depreciation and amortization (D\&A) has become an important determinant of credit rating in the last ten years. This latter result suggests that relying on EBITDA when evaluating credit risk — as is commonly done in practice-sacrifices significant earnings-related information. The synthetic credit ratings generated by the model perform very well in explaining agency ratings and CDS spreads, suggesting that fitted values for unrated companies are likely to be reasonably precise and can therefore serve as a substitute for agency ratings when the latter are unavailable.

If the extent to which agency ratings reflect credit-relevant information is not uniform across companies, the difference between the synthetic and agency ratings may help predict changes in agency ratings. This may be the case for at least six reasons. First, credit rating agencies (CRAs) may not pay the same attention to all firms; for example, they may pay less attention to small companies. Second, CRAs review and adjust credit ratings on a periodic rather than continuous basis, so ratings do not adjust immediately to changes in credit quality. Third, CRAs care about the stability of the ratings in addition to their informativeness, which could affect the timeliness of the ratings (e.g., Lofflet, 2004; Altman and Rijken, 2004; Cantor and Mann, 2007). ${ }^{2}$ Fourth, CRAs may deliberately bias the ratings or delay downgrading ratings fearing losing the issuer's business, and this effect may vary across issuers (e.g., Jiang, Stanford and Xie, 2013). Fifth, agency ratings may reflect selection bias resulting from issuers' engaging in rating shopping, an effect which is likely to vary across issuers (Kronlund, 2017). Sixth, although the synthetic

\footnotetext{
${ }^{2}$ White (2013) explains this as follows: "the CRAs' sluggishness with respect to changing ratings is a long-standing "cultural" phenomenon that extends at least as far back as the 1930s ..., when the investor-pays model was the standard and thus well preceded the advent of the issuer-pays model. Instead, the phenomenon is best understood as follows: The major CRAs have a belief that the appropriate approach is "rating through the cycle," which means ignoring short run perturbations in an issuer's financial position that are likely to be reversed. The CRAs believe that this relative stability better serves bond investors, who want accuracy but who also do not want to incur the transactions costs of selling and then rebuying (or vice versa) bonds based on short-term perturbations that are subsequently reversed."
} 
ratings estimated in this study are based on easily available information, which CRAs likely consider when adjusting ratings, the calculation of the synthetic ratings involves a systematic fitting of ratings to their determinants across all rated companies. CRAs likely consider the relative credit quality of companies when adjusting ratings, but they may not do so as systematically as is done in this study (cross sectional ordered logit regressions with transformed variables, estimated across all rated companies).

Indeed, I find that differences between the synthetic and agency ratings predict changes in agency ratings in many subsequent months, especially for small companies. The finding that the ability of synthetic ratings to predict rating changes is stronger for small companies is consistent with the conjecture that small companies receive less attention from CRAs. The predictive-ability of synthetic ratings is very significant, both statistically and economically, and while it monotonically declines over the forecasting horizon, the difference between the synthetic and agency ratings predicts changes in agency ratings as far as 24 months later. The cumulative adjustment is significant - after 24 months, it is about $20 \%$ (15\%) of the initial difference for small (large) companies. Finally, there is no evidence of substantial improvement over the last thirty years in the timeliness of agency ratings with respect to the information in synthetic ratings.

I also find that synthetic credit ratings help explain CDS spreads even after controlling for agency ratings, providing further support for the hypothesis that agency ratings do not fully impound the information in the synthetic credit ratings. Still, the overall explanatory power of agency ratings for CDS spreads is larger than that of the synthetic ratings, consistent with the fact that CRAs consider additional financial ratios besides those used in estimating the synthetic ratings, as well as qualitative factors (e.g., narrative disclosure, corporate governance, regulatory issues such as antitrust or environmental problems, union-related labor issues, etc.) and 
confidential information. However, in recent years the difference between the incremental information provided by agency ratings and that provided by the synthetic ratings has substantially declined, possibly due to new SEC regulation that limits CRAs' ability to obtain confidential information from rated companies. ${ }^{3}$

Given the inefficiency of agency ratings with respect to the information in the synthetic ratings, and the role that ratings play in pricing CDS (e.g., Hull, Predescu and White, 2004; Micu, Remolona and Wooldridge, 2004), it is possible that CDS spreads are also inefficient with respect to the information in the synthetic credit ratings. To test this hypothesis, I examine whether the difference between the synthetic and agency ratings predict subsequent changes in CDS spreads. I find no evidence of predictive ability. It appears that CDS investors recognize the inefficiencies of agency ratings and price the incremental information contained in the synthetic ratings (or in the credit proxies used to estimate the synthetic ratings) in a timely fashion.

To the extent that credit-related information affects equity value (e.g., Holthausen and Leftwich, 1986), and equity investors do not fully price it (e.g., Campbell, Hilscher and Szilagyi, 2008), the difference between the synthetic and agency ratings may predict subsequent stock returns. Again, I find no evidence of predictive ability, suggesting that equity investors price the credit-related information contained in the synthetic ratings in a timely fashion.

The findings of this study have several implications. First, they demonstrate that reasonably precise estimates of credit ratings can be derived for unrated companies. Second, they show that

\footnotetext{
${ }^{3}$ On September 29, 2010, the Securities and Exchange Commission (SEC) issued a final rule release (No. 33-9146), "Removal from Regulation FD of the Exemption for Credit Rating Agencies." The removal of the exemption, which became effective in January 2011, possibly reduced the ability of rating agencies to obtain confidential information from issuers. Regulation FD provides that when an issuer discloses material nonpublic information, it generally must make public disclosure of that information. Under the exemption, issuers were not required to make the public disclosure if the disclosure was made to a credit rating agency. The extent to which the removal of the exemption actually limits the CRAs access to confidential information is unclear (see, e.g., Bullard, 2016).
} 
financial statement analysis provides information relevant for evaluating credit quality, incremental to that in agency ratings. Third, the results suggest that credit agencies should be able to easily improve the efficiency of their ratings. Such an improvement is particularly warranted these days, given that (1) the incremental information provided by agency ratings relative to synthetic ratings has declined substantially in recent years; (2) investors' ability to obtain and process financial information in a timely fashion has improved substantially; and (3) recent regulatory changes have reduced regulatory reliance on agency ratings, thus increasing the relative importance of the information role of agency ratings (compared to their role in prudential regulation). ${ }^{4}$

The paper proceeds as follow. Section 2 develops the synthetic ratings model. Section 3 empirically evaluates the accuracy of the synthetic ratings in terms of their ability to explain contemporaneous agency ratings and CDS spreads. Section 4 examines the efficiency of agency ratings with respect to the information contained in the synthetic ratings, and Section 5 investigates the timeliness of the market pricing of this information. Section 6 concludes the paper.

\section{Modelling synthetic credit ratings}

Similar to many previous credit rating studies, I use ordered logit regressions to estimate the synthetic ratings. ${ }^{5}$ However, unlike most previous studies (e.g., Kaplan and Urwitz, 1979; Blume,

\footnotetext{
${ }^{4}$ Regulators of some institutional investors (e.g., pension trusts, insurance companies) rely on agency ratings in restricting the investments of those entities and/or in setting their capital requirements. Section 939A of the DoddFrank Act requires federal regulators to remove references to the credit ratings of Nationally Recognized Statistical Rating Organizations (NRSRO). Since then, federal regulators have rewritten most rules relying on NRSRO ratings (Soroushian, 2016). Regulatory reliance on agency ratings still applies to some federally-regulated institutional investors (e.g., pension trusts) as well as to state-regulated institutional investors (e.g., insurance companies) and to institutions subject to other regulation (e.g., by exchanges).

${ }^{5}$ Ederington (1985) shows that the ordered logit model performs better than OLS, probit, and multivariate discriminate analysis in out-of-sample prediction of credit ratings. Compared to probit, logit is less sensitive to
} 
Lim and MacKinlay, 1998), I use a parsimonious model, and I log-transform most variables. Using logs gives the advantage of implicitly accounting for a larger set of rating determinants. For example, $\log (a), \log (b), \log (c)$ and $\log (d)$ span the same information as $\log (a / b), \log (a / c), \log (a / d)$, $\log (\mathrm{b} / \mathrm{c}), \log (\mathrm{b} / \mathrm{d}), \log (\mathrm{c} / \mathrm{d}), \log (\mathrm{a}), \log (\mathrm{b}), \log (\mathrm{c})$, and $\log (\mathrm{d})$. This is important because some quantities affect the ratings both in absolute and relative sense, and in various ways. For example, the absolute magnitude of EBITDA may affect the rating because it serves as a size proxy, while the magnitude of EBITDA relative to interest expense and assets may capture interest coverage and profitability, respectively, which are also relevant for determining the rating. Using logs effectively allows the data to determine the weights on the various transformations (e.g., the size of EBITDA, interest coverage, and profitability). Having a small number of predictors mitigates some statistical problems (e.g., instability of the coefficients, multicollinearity, low statistical significance), and it enables me to (1) use cross-sectional (instead of panel) regressions when estimating the synthetic credit rating, (2) partition the sample, and (3) examine the relation with CDS spreads (which have lower data availability). ${ }^{6}$ Another advantage of the log transformation is that it reduces the skewness of the variables (e.g., of interest coverage; see Blume, Lim and MacKinlay, 1998, and Amato and Furfine 2004), thereby increasing their explanatory power.

While the log transformation offers several advantages, it does have an important shortcoming - it can only be applied to positive numbers. This disadvantage is particularly important when measuring profitability—a key rating determinant—because companies often report losses. I deal with this issue by focusing on earnings before interest, taxes, depreciation, and

outliers as the logistic distribution has heavier tails than the normal distribution. In any case, the results are qualitatively similar when using ordered probit regressions instead.

${ }^{6}$ The intuition is as follows. When too many explanatory variables are used (relative to the number of observations), the model is effectively fitted not only to the underlying structure but also to the "noise" in the dependent variable, leading to bad prediction results because the noise in future values is unrelated to the noise in past values. 
amortization (EBITDA), which is less likely to be negative compared to other earnings metrics (e.g., earnings before interest and taxes, or EBIT). In addition, instead of using the most recent EBITDA, I use its median value over the last three years, which is less likely to be negative and is often a better indicator of long-term profitability as it smooths out transitory shocks. Still, because the cost of fixed assets ultimately reduces the funds available to service debt, I include depreciation as a separate rating predictor. ${ }^{7}$

For non-negative variables, the log transformation may still be problematic if there is a significant frequency of zeros or close to zero values. As with negative numbers, the log of zero is undefined, and logs of positive numbers that are close to zero are outliers. For example, a company may pay no interest but its credit rating may still be relevant to lessors or to other creditors. To address this issue, I restrict the sample to firm-month observations with either total assets or revenue greater than $\$ 25$ million in December 2016 prices. I also set the values of variables whose pre-transformation value is non-negative but less than one equal to one (i.e., I winsorize the logtransformed variables at zero, applying the winsorization only to non-negative pre-transformation values).

To generate synthetic ratings, each month I estimate the following ordered logit regression model:

$$
\begin{aligned}
g(\operatorname{Pr}(\text { Rating } & \leq i)) \\
& =\alpha_{i}+\beta_{1} \log \left(M_{-} E B I T D A\right)+\beta_{2} \log (\text { Interest })+\beta_{3} \log (D \& A) \\
& +\beta_{4} \text { TangLev }+\beta_{5} \log (\text { MVEquity })+\beta_{6} \text { RetVolat }
\end{aligned}
$$

\footnotetext{
${ }^{7} \mathrm{Li}$ (2016) finds that while earnings-based covenants in loan contracts are typically based on performance measures close to EBITDA, EBITDA is less useful in explaining credit risk than earnings before interest and tax expenses (EBIT).
} 
for $i=1,2, \ldots, 6 . g($.$) is the logit function (the inverse of logistic function), and Rating is a numeric$ measure of credit rating (Rating $=1$ for AAA, ..., Rating $=7$ for $\mathrm{CCC}+$ and below; full description is provided in the next section) ${ }^{8} M_{-} E B I T D A$ is the median value of EBITDA (Compustat's OIBDP) over the last three fiscal years; Interest is interest cost (interest expense plus capitalized interest, Compustat's XINT) over the most recent four quarters or the most recent annual report if the trailing four quarter value is missing; ${ }^{9} D \& A$ is depreciation and amortization (Compustat's DP) over the most recent four quarters or the most recent annual report if the trailing four quarter value is missing; TangLev is tangible leverage, measured as the ratio of total liabilities (Compustat's LT) to the book value tangible assets (total assets minus intangible assets, Compustat's AT - INTAN) as of the most recent quarter or the most recent annual report if quarterly INTAN is missing; ${ }^{10}$ MVEquity is the market value of common equity at the end of the month; RetVolat is return volatility, estimated using the 60 most recent monthly stock returns through the end of the month (a minimum of 30 observations is required).

EBITDA is a proxy for the funds generated in operations, which can be used to pay interest and principal. It is typically considered the most important metric when evaluating debt capacity and ability to service debt, which are the primary attributes that credit ratings purport to measure.

\footnotetext{
${ }^{8}$ This model is essentially a set of six related regression equations estimated simultaneously using maximum likelihood. The explanatory variables of the six equations are identical, and the coefficient on each explanatory variable is restricted to be identical across the six equations. Each equation also includes an unrestricted intercept $\left(\alpha_{i}, i=1,2, \ldots, 6\right)$. The dependent variable in each equation is a function $(\mathrm{g}($.$) , the logit function) of the probability that$ Rating is equal to or smaller (i.e., better) than $i$, for the first six values of $i, i=1,2, \ldots, 6$ (for $\mathrm{i}=7$, the probability is one). $g($.$) is a monotonically increasing function with domain (0,1)$ and range $(-\infty,+\infty)$, so high values of $g(\operatorname{Pr}($ Rating $\leq i))$ for a given $i$ imply high credit quality. Thus, the $\beta$ coefficients should be positive (negative) for variables that are positively (negatively) related to credit quality. $\alpha_{i+1}-\alpha_{i}$, for $i=1,2, \ldots, 6$, measures the increase in $\mathrm{g}($.$) associated with \operatorname{Pr}($ Rating $=i+1)$.

${ }^{9}$ I measure trailing four quarters data as the year-to-date (YTD) value plus the previous year annual value minus the previous year YTD value. Prior to 1995, YTD income statement data were generally unavailable on Compustat, so for that period I measure the trailing four quarter data using quarterly information.

${ }^{10}$ If INTAN is missing in both the quarterly and annual data, I measure TangLev as the ratio of total liabilities to total assets as of the most recent quarter.
} 
Depreciation and amortization (D\&A) is included in the model to capture the cost of fixed assets, which EBITDA ignores. A portion of the EBITDA has to be committed to replacing fixed assets in order to continue to generate EBITDA. In other words, EBITDA is not sustainable if the firm does not invest to maintain operating capacity.

Credit analysts focus on EBITDA rather than EBIT (i.e., EBITDA minus D\&A) primarily due to accounting distortions in measuring D\&A. ${ }^{11} \mathrm{D} \& \mathrm{~A}$ is measured using subjective assumptions (useful lives, residual value), which can be manipulated by managers. In addition, D\&A is measured based on the asset's historical cost, which is typically a poor proxy for current cost due to inflation. Importantly, the inflation-related distortion depends on the timing of asset acquisition, which varies across companies and thus reduce the comparability of EBIT. Amortization is even more problematic than depreciation because it relates primarily to assets acquired in business combinations (most internally-developed intangibles are not recognized), and unlike fixed assets some of the cost of replacing intangible assets is included in EBITDA (for example, advertising costs, which reduce EBITDA, effectively maintain the value of an acquired trade name that is subject to amortization). ${ }^{12}$

The D\&A-related issues discussed above suggest that while the cost of fixed and intangible assets is relevant for evaluating credit quality, a dollar of D\&A may have a different effect on

\footnotetext{
${ }^{11}$ A related reason is that debt covenants are more commonly based on EBITDA than on EBIT, partially because of the accounting distortion in measuring D\&A. Li (2016) hypothesizes and provides evidence that contracting parties choose EBITDA over EBIT to make the performance measure less sensitive to investment activities, which can be controlled through other contractual terms such as a restriction on capital expenditures.

${ }^{12}$ Another often-mentioned reason for excluding D\&A is that they represent sunk cost or a non-cash expense and therefore do not reduce the funds that are available to service debt. This argument is problematic because companies are not able to indefinitely avoid replacing depreciating assets.
} 
credit rating than a dollar of other operating expenses. By including EBITDA and D\&A separately, the model accommodates such variability.

Interest reflects the amount of debt (financial leverage) as well as its cost (interest rate), both affecting the probability of default. The inclusion of both $M_{-} E B I T D A$ and Interest, measured in logs, is equivalent to also including the log of interest coverage (EBITDA/Interest), which is considered a key credit rating determinant (e.g., Blume, Lim and MacKinlay, 1998). In addition, the inclusion of both Interest and the market value of equity (MVEquity), measured in logs, is equivalent to also including the log of Interest/MVEquity, which is proportional to both the level and cost of financial leverage (Debt/MVEquity and Interest/debt, respectively). ${ }^{13}$

The tangible leverage ratio (TangLev) adds to the other leverage-related measures in several ways. ${ }^{14}$ First, interest-bearing liabilities (debt) are not the only fixed claims on the firm's assets. For many companies, operating liabilities—including credit from suppliers (e.g., accounts payable), employees (e.g., accrued compensation), and customers (e.g., unearned revenue) —are at least as significant as interest-bearing debt. Similar to debt, operating liabilities represent fixed claims that have to be paid. By including all liabilities in TangLev, this metric captures all recognized fixed claims. In addition, by excluding intangible assets, TangLev may provide incremental information relative to the other leverage measures because: (1) Intangible assets typically have low or even no liquidation value; (2) intangible assets generate more volatile earnings streams than other assets (e.g., Kothari, Laguerre and Leone, 2002); and (3) intangible assets are only recognized when acquired, reducing their comparability across firms.

\footnotetext{
${ }^{13}$ Because the model is estimated using cross-sectional regressions, differences in interest rates across the observations are due primarily to differential credit risk, not to market fluctuations in interest rates.

14 To reduce multicolinearity (Amato and Furfine, 2004), I do not apply the log transformation to TangLev because liabilities, tangible assets, and the market value of equity (another included variable) are all highly correlated.
} 
The various leverage measures included in the model (directly or indirectly, as explained above) capture several sources of risk that credit ratings attempt to quantify. Liabilities are claims that have to be met, and so high financial leverage implies that a relatively small equity cushion is available to absorb losses. Financial leverage also reduces financial flexibility. Because debt capacity is restricted, high-debt firms have limited ability to borrow additional funds if the need for such borrowing arises. In addition, high-debt firms are dependent on debt markets for continued refinancing and so are more sensitive to changes in interest rates, credit spreads, and funds availability. Financial leverage also affects operating risks by magnifying the impact of operating shocks on the financial position of the firm. When firms' fortunes deteriorate, customers, suppliers, employees and other stakeholders often require better terms when transacting with the firm, and in some cases are not willing to do business with the company at all, thus exacerbating the negative shock that caused the initial decline in fortune.

Market value of equity (MVEquity) is an important predictor of credit ratings for several reasons. Compared to small firms, large firms are better diversified, are more likely to use financial hedging techniques, and are more profitable. They also have greater financial flexibility, lower information risk, and lower variability in profitability and growth rates. In addition, given that I measure leverage relative to tangible assets (TangLev), including the market value of equity as an additional explanatory variable helps capture the additional protection that economic intangibles provides (albeit smaller than that provided by tangible assets, as explained earlier). MVEquity is also correlated with the strength of corporate governance.

Stock return volatility (RetVolat) serves as a proxy for asset risk, which is an important determinant of credit risk because it affects the probability that the value of the assets will decline below the book value of the liabilities and trigger default (Merton, 1974). Although RetVolat 
measures equity risk, which is higher than asset risk, the difference is determined primarily by leverage, which I control for using the other predictors as discussed above.

The literature has identified many additional financial and non-financial rating determinants, including corporate governance (e.g., Bhojraj and Sengupta, 2003; AshbaughSkaife, Collins and LaFond, 2006) and macroeconomic factors (e.g., Amato and Furfine, 2004). I do not include corporate governance variables (other than size, which is correlated with the strength of corporate governance), because their explanatory power is typically low and my objective is to generate predictions rather than to test hypotheses about rating determinants. As explained earlier, adding a variable that has low explanatory power may lower the accuracy of outof-sample prediction. I do not include macroeconomic factors because the synthetic rating model is estimated cross-sectionally, and so there is no variation in macro factors within each regression.

\section{Estimating and evaluating the synthetic ratings}

The data for the analysis are obtained from the Compustat Ratings file (agency ratings), the Compustat Fundamentals Quarterly and Annual files (accounting based rating determinants), the CRSP monthly file (market based rating determinants and stock returns), and the Markit CDS database (CDS spreads). Ratings are available at monthly frequency for the period December 1985 through January 2017 (374 months), and accordingly the sample for the main analysis covers that period. CDS data are available since 2002, so analyses that use these data cover the period January 2002 through January 2017 (181 month). Financial firms (GIC sector 40), utilities (GIC sector 55) and small firms (total assets and revenue are each less than 25 million USD in December 2016 prices) are excluded. Financial firms are excluded because the concepts and measures of operating profitability and leverage are different for this sector. Utilities are excluded because the impact of 
rate regulation makes profitability less relevant for determining rating. Very small firms are omitted to reduce the frequency of zero values for variables to which the log transformation is applied, and because financial metrics are often poorly-behaved for these firms. To further mitigate the effects of outliers, I trim extreme values of the rating predictors. ${ }^{15}$

To identify the available financial information each month, I use the following procedure. For post 1993 observations, I conservatively assume that financial information becomes available after the $10-\mathrm{Q} / \mathrm{K}$ filing date, which I obtain from the SEC's EDGAR system. ${ }^{16}$ For pre-1994 observations, and for post 1993 observations with unavailable filing dates, I estimate the availability date using the earnings announcement date (from Compustat) as follows: for fiscal quarters one through three, I assume that the filing occurs within 30 days after the earnings announcement date, while for the fourth fiscal quarter I assume that the filing occurs within 65 days after the earnings announcement date. I further assume that accounting information becomes available within 55 (100) days from quarter end for the first three (fourth) fiscal quarters, but no earlier than the earnings announcement date. These assumptions are based on a careful examination of the gaps between fiscal quarter end, earnings announcement date, and the $10-\mathrm{Q} / \mathrm{K}$ filing date over time. They are selected to assure that in at least 99 percent of cases, any error is on the conservative side. Moreover, in most cases financial information becomes available prior to

\footnotetext{
${ }^{15}$ Extreme values of the variables are identified using the following procedure. For each variable, I calculate the $1^{\text {th }}$ and $99^{\text {th }}$ percentiles of the empirical distribution (P1 and P99 respectively) and trim observations outside the following range: $\mathrm{P} 1-1 \times(\mathrm{P} 99-\mathrm{P} 1)$ to $\mathrm{P} 99+1 \times(\mathrm{P} 99-\mathrm{P} 1)$. For normally distributed variables, this range covers approximately 7 standard deviations from the mean in each direction $(=2.33+1 \times(2.33-(-2.33))$, which includes more than $99.99 \%$ of the observations. For variables with relatively few outliers, the percentage of retained observations is also very high (often 100\%). However, for poorly-behaved variables a relatively large proportion of the observations is deleted.

${ }^{16} 10-\mathrm{Q} / 10-\mathrm{K}$ filing dates are available from Edgar for fiscal quarters ending after the third calendar quarter of 1993.
} 
the $10-\mathrm{Q} / \mathrm{K}$ filing date, either at the time of the earnings announcement or in $8-\mathrm{K}$ filings (Lerman and Livnat, 2010).

The Compustat Ratings file contains three alternative measures of credit quality: S\&P Domestic Long Term Issuer Credit Rating (SPLTICRM), S\&P Subordinated Debt Rating (SPSDRM), and S\&P Domestic Short Term Issuer Credit Rating (SPSTICRM). Similar to prior studies, I use the long-term issuer credit rating. Panel A of Table 1 presents the frequency table of this rating variable. The number of available ratings is 326,034 , less than a third of the total number of observations that satisfy the data requirements $(1,074,601)$, indicating the importance of generating synthetic ratings. Figure 1 shows that the number of observations with available agency ratings and accounting and market data needed to construct the rating predictors has increased from about 650 each month in the first 10 years (through the mid-1990s), to about 1,000 each month over the last 20 years.

As shown in Panel A of Table 1, there are 22 different credit ratings, for many of which the number of observations is relatively small (e.g., the categories $\mathrm{AA}+, \mathrm{CCC}+, \mathrm{CCC}, \mathrm{CCC}-, \mathrm{CC}$, $\mathrm{C}$, and $\mathrm{D}$ constitute less than $1 \%$ of the observations each). Because an excessive number of levels in multinomial models reduces the precision of predictions (particularly when some levels have low frequency), I define a numeric transformation of SPLTICRM (denoted Rating), which is calculated as follow: $\mathrm{SPLTICRM}=\mathrm{AAA} \Rightarrow$ Rating $=1, \mathrm{SPLTICRM}=\mathrm{AA}+, \mathrm{AA}$, or $\mathrm{AA}-\Rightarrow$ Rating $=2$, SPLTICRM $=\mathrm{A}+, \mathrm{A}$, or $\mathrm{A}-\Rightarrow$ Rating $=3, \mathrm{SPLTICRM}=\mathrm{BBB}+, \mathrm{BBB}$, or $\mathrm{BBB}-\Rightarrow$ Rating $=4$, SPLTICRM $=\mathrm{BB}+, \mathrm{BB}, \mathrm{BB}-\Rightarrow$ Rating $=5$, SPLTICRM $=\mathrm{B}+, \mathrm{B}, \mathrm{B}-\Rightarrow$ Rating $=6$, and SPLTICRM $=\mathrm{CCC}+, \mathrm{CCC}, \mathrm{CCC}-, \mathrm{CC}, \mathrm{C}$, or $\mathrm{D} \Rightarrow$ Rating $=7$. Panel $\mathrm{B}$ of Table 1 reports the frequency distribution of Rating. Unlike for SPLTICRM, each of the categories of Rating has a substantial number of observations. 
Table 2 presents summary statistics from the cross-sectional (monthly) ordered logit regressions of Equation (1). For each coefficient, the statistics reported are the time-series mean of the coefficients from the monthly regressions (mean(coef.)), the t-statistic of the mean coefficient ( $\mathrm{t}($ mean(coef.)), the ratio of the time-series mean to its standard error), and the timeseries median of the regressions' z-statistics (median(z(coef.))). All coefficients have the expected sign and are highly significant. Most significant are the market based variables—size (MVEquity) and volatility (RetVolat)—but profitability (M_EBITDA) and interest (Interest) are also highly significant.

Figure 1 plots the R-squared from the cross-sectional regressions over time. Unlike prior studies, the R-squared in this study is consistently high throughout the sample period. Jorion and Zhang (2009) find that the R-squared from ordered probit regressions that use accounting information to predict credit ratings has declined substantially since the mid-1990s, and they attribute this result to a decline in the quality of accounting information. Indeed, over the last three decades earnings volatility has been gradually increasing due to accounting and economic changes (e.g., Givoly and Hayn, 2000; Corrado and Hulten, 2010) as well as to changes in the characteristics of public companies (e.g., Fama and French, 2004). The increase in earnings volatility has caused a decline in the ability of reported earnings to capture the true earnings power of companies, leading to a decline in their explanatory power for credit ratings. To mitigate this effect, I measure profitability using the median value of EBITDA over the last three years. EBITDA excludes non-operating and special items, which have contributed substantially to the increase in earnings volatility (e.g., Dechow and Ge, 2006). In addition, median EBITDA over a 
three years period is much less volatile than annual EBITDA. Due to these modelling choices, the R-squared in this study is consistently high throughout the sample period. ${ }^{17}$

Figure 2 plots the z-statistics of the coefficients on the explanatory variables over time. All coefficients other than depreciation and amortization $(D \& A)$ were consistently significant throughout the sample period. While D\&A was insignificant from the mid-90s through the mid2000s, it became highly significant after that period. The increase in the significance of D\&A over the last decade highlights the importance of considering D\&A, which is often ignored by credit analysts that focus on EBITDA.

To gauge the economic significance of the explanatory variables, Table 2 reports the timeseries mean and median of the product of each regression coefficient and the cross-sectional standard deviation of the corresponding explanatory variable. This product term measures the economic significance of the explanatory variable because it indicates the extent to which cross sectional variation in that variable contributes to the cross sectional variation in the dependent variable. Given that the average distance between the credit rating cuts is approximately 3 units $\left(\alpha_{2}-\alpha_{1}=2.6, \alpha_{3}-\alpha_{2}=3.1, \alpha_{4}-\alpha_{3}=3.1, \alpha_{5}-\alpha_{4}=3.2, \alpha_{6}-\alpha_{5}=6.6 ;\right.$ see footnote 8), dividing the product term by 3 gives a rough proxy for the effect on the rating. For example, a one standard deviation increase in Interest lowers the credit rating by approximately 0.3 units $(=1.012 / 3)$, or approximately one letter notch (most numeric rating consist of 3 letter ratings each). Figure 3 plots the economic significance of the explanatory variables (the product terms) over time. The ranking and trends of the variables are generally similar to those in Figure 2, which plots the z-statistics. One difference is that EBITDA and D\&A (since the mid-2000s) appear even more

\footnotetext{
${ }^{17}$ As explained in Section 2, another advantage of using median EBITDA instead of the most recent EBITDA is that median EBITDA is much less likely to be negative, which is important because logs of non-positive numbers are undefined.
} 
important in Figure 3, which considers their cross-sectional variation in addition to the magnitude of the regression coefficient. Figure 3 indicates that the economic significance of EBITDA in explaining rating is as high as that of size, and that over the last ten years the economic significance of D\&A has been almost as high as that of interest.

Having estimated the regression coefficients, I next calculate the synthetic rating of each firm-month observations with available values for the explanatory variables. Specifically, for each firm-month observation, I (1) calculate the fitted value $(g(\operatorname{Pr}(\operatorname{Rating} \leq i)))$ for each $i=1,2, \ldots, 6$; (2) apply the logistic function (the inverse of $g($.$) , the logit function) to the fitted values to get the$ estimated $\operatorname{Pr}($ Rating $\leq i)$ for each $i$; and (3) measure the synthetic rating (SRating) for that firmmonth observation as the rating corresponding to the largest increase in the cumulative distribution function of Rating. To evaluate the accuracy of the predictions, I present in Table 3 the distribution of agency rating conditional on each of the seven possible values of synthetic rating. The sample for this analysis consists of 324,533 observations with available agency and synthetic ratings. As shown, the model performs very well. For example, $70 \%$ of the observation with synthetic rating 1 (AAA) have agency credit rating of 1 , and $59 \%$ of the observations with synthetic rating 4 have agency credit rating of 4. In addition, the Spearman and Pearson correlations between the agency and synthetic ratings across all the observations are 0.849 and 0.846 , respectively. ${ }^{18}$

To further evaluate the informativeness of the synthetic ratings, I run regressions that are nested in the following model:

$$
\text { CDS }=\beta_{0}+\beta_{1} \text { Rating }+\beta_{2} \text { SRating }+\varepsilon
$$

\footnotetext{
${ }^{18}$ While I use the same observations to generate and evaluate the synthetic ratings, the in-sample bias is negligible. If the model is re-estimated excluding the observation for which the synthetic rating is calculated, the impact on the estimated coefficients and therefore on the synthetic rating is negligible. Accordingly, the out-of-sample results are essentially identical to the reported results (I verified this empirically for many subsamples).
} 
Where CDS represents one of three alternative measures of credit risk derived from CDS spreads: CDS_Spread5, Excess CDS_Spread5, and CDS Implied Rating.

The first CDS measure, CDS_Spread5, is the amount paid by the protection buyer to the protection seller in a five year CDS contract, measured in annualized percentage points. ${ }^{19}$ It reflects both the level of credit risk and the price of credit risk. The level of credit risk depends on the probability of default and the recovery rate in case of default. The price of credit risk depends on economy-wide risk aversion, which changes over time (for example, it increases at times of market dislocation) as well as on firm-specific systematic risk (for example, two companies with the same probability of default and recovery rate may have different CDS spreads if the default is expected to occur at different states of the economy).

Using CDS spreads to evaluate the accuracy of credit ratings involves at least three issues. First, credit ratings measure the level of credit risk while, as noted above, CDS spreads reflect the price of credit risk in addition to the level of credit risk. Second, CDS spreads reflect point-in-time estimates of credit risk while credit ratings reflect through-the-cycle evaluation of credit risk (e.g., Lofflet, 2004; Altman and Rijken, 2004; Cantor and Mann 2007). Third, CDS spreads reflect both the probability of default and the recovery rate, while issuer credit ratings may not reflect the recovery rate. ${ }^{20}$

\footnotetext{
${ }^{19} \mathrm{CDS}$ is a credit derivative transaction in which two parties enter into an agreement, whereby one party (the protection buyer) pays the other party (the protection seller) periodic payments for the specified life of the agreement. The Protection Seller makes no payment unless a credit event relating to a predetermined reference asset occurs. If such an event occurs, it triggers the protection seller's settlement obligation, which can be either cash or physical.

${ }^{20} \mathrm{~S} \& \mathrm{P}$ provides both issue and issuer credit ratings. In describing issue credit ratings, $\mathrm{S} \& \mathrm{P}$ notes (https://www.standardandpoors.com/en_US/web/guest/article/-/view/sourceId/504352): "Issue credit ratings are based, in varying degrees, on S\&P Global Ratings' analysis of the following considerations:

- The likelihood of payment--the capacity and willingness of the obligor to meet its financial commitment on a financial obligation in accordance with the terms of the obligation;

- The nature and provisions of the financial obligation, and the promise we impute; and
} 
To mitigate the effect of variation in economy-wide risk aversion on CDS spread, I use the difference between CDS_Spread5 and its cross-section average across all firms as an alternative CDS measure (Excess CDS_Spread5). To address all three concerns discussed above (but at the price of some vagueness regarding the exact calculation of the variable), I use the CDS-implied credit rating (CDS Implied Rating), which Markit calculates "by comparing the issuer's five year senior standard trading convention spread to the five years spreads of the sector curves and applying the rating of the logarithmically nearest rating curve specific to that sector." I convert the CDS Implied Rating to a numerical scale using the same approach used to convert the agency ratings.

CDS contracts are distinguished along several dimensions, including maturity, seniority of the reference instruments, and type of credit events that trigger the default swap contract. Similar to previous studies (e.g., Longstaff, Mithal and Neis, 2005), I use the five year maturity, which is the most common contract. I restrict the CDS data to Senior Unsecured Debt (tier $=$ SNRFOR), which is by far the most common seniority (more than $90 \%$ of the observations). Because the distribution of credit events that trigger settlement under the CDS contract is relatively uniform, I

- The protection afforded by, and relative position of, the financial obligation in the event of a bankruptcy, reorganization, or other arrangement under the laws of bankruptcy and other laws affecting creditors' rights.

Issue ratings are an assessment of default risk, but may incorporate an assessment of relative seniority or ultimate recovery in the event of default. Junior obligations are typically rated lower than senior obligations, to reflect the lower priority in bankruptcy, as noted above. (Such differentiation may apply when an entity has both senior and subordinated obligations, secured and unsecured obligations, or operating company and holding company obligations.)"

In contrast, issuer credit ratings are described as "a forward-looking opinion about an obligor's overall creditworthiness. This opinion focuses on the obligor's capacity and willingness to meet its financial commitments as they come due. It does not apply to any specific financial obligation, as it does not take into account the nature of and provisions of the obligation, its standing in bankruptcy or liquidation, statutory preferences, or the legality and enforceability of the obligation." Thus, while issue credit rating reflect both the probability of default and the loss given default, it is not clear if and to what extent the issuer credit rating reflects loss given default. 
measure the CDS variables using their median value across the four credit events on the last day of each month. ${ }^{21}$

The results for the three CDS measures, reported in the three panels of Table 4, are similar. The first two regressions in each panel evaluate the explanatory power of agency ratings and synthetic ratings separately. For each of the three CDS measures, each of the two rating variables performs very well, with R-squared in excess of $30 \%$ in all cases. Still, the overall explanatory power of agency ratings is larger than that of the synthetic ratings. This result is consistent with the fact that CRAs consider additional financial ratios besides those used in estimating the synthetic ratings, as well as qualitative factors (e.g., narrative disclosure, corporate governance, regulatory issues such as antitrust or environmental problems, union-related labor issues, etc.) and confidential information (e.g., Jorion, Liu and Shi, 2005). The third regression in each panel includes both the agency and synthetic ratings as explanatory variables. As shown, synthetic ratings help explain each of the CDS variables even after controlling for agency ratings, and their contribution is highly significant, both statistically and economically. The t-statistics for the synthetic ratings, which are calculated using two-ways (firm and month) clustered standard errors (Petersen, 2009), are about eight, and the size of the synthetic rating coefficient is more than half

\footnotetext{
${ }^{21}$ There are four credit events that trigger settlement under the CDS contract: Restructuring (about $20 \%$ of the observations), modified restructuring (35\%), modified modified restructuring (15\%), and no restructuring (30\%). Restructuring is a "soft" event, whereby the loss to the owner of the reference obligation is not obvious. In addition, Restructuring often retains a complex maturity structure, so that debt of different maturities may remain outstanding with significant differences in value. The following are the different types of Restructuring clauses: Full Restructuring (CR): This allows the Protection Buyer to deliver bonds of any maturity after restructuring of debt in any form occurs. This type of clause is more prevalent in Asia. Modified Restructuring (MR): limits deliverable obligations to bonds with maturities of less than 30 months after a credit event. Modified Modified Restructuring (MM): This is a "modified" version of the Modified Restructuring clause whereby deliverable obligations can mature up to 60 months (5 years) following the credit event. This type of clause if more prevalent in Europe. No Restructuring (XR): This option excludes restructuring altogether from the CDS contract, eliminating the possibility that the Protection Seller suffers a "soft" Credit Event that does not necessarily result in losses to the Protection Buyer. No-R protection typically trades cheaper than Mod-R protection. Following the implementation of SNAC, this clause is mainly traded in North America.
} 
the size of the agency rating coefficient in all cases. These results suggest that agency ratings do not reflect a substantial portion of the information contained in the synthetic ratings.

To evaluate changes over time in the overall and incremental information of agency and synthetic ratings, I re-estimate Equation (2) using cross-sectional regressions each month during the period for which the CDS spreads are available (January 2002 through January 2017). Figure 4 plots the coefficients from regressing CDS_spread5 on the agency and synthetic ratings, as well as the difference between the two coefficients. As shown, the synthetic ratings provided incremental information in each of the 181 months. Moreover, in two sub-periods - the financial crisis and the last three years - the magnitude of the coefficients on the agency and synthetic ratings were similar, suggesting that during those periods CDS investors did not view agency ratings as providing much incremental information over the credit risk proxies used to construct the synthetic rating. For the financial crisis period, a potential explanation for this result is the deterioration in investors' confidence in agency ratings. The result for the last three years possibly reflects the effect of SEC Release No. 33-9146, Removal from Regulation FD of the Exemption for Credit Rating Agencies, which became effective in January $2011 .^{22}$ If this regulation indeed limits the CRAs access to confidential information (which is unclear, see, e.g., Bullard 2016), its effect on the confidential information reflected in agency ratings was probably protracted as the significance of confidential information obtained by the CRAs prior to January 2011 declined over time. The difference between the agency and synthetic ratings coefficients, which was highly significant for the sample period (t-statistic of 17.4), was indistinguishable from zero in the last three years (January 2014 through January 2017). Moreover, the change in the average difference between the agency and synthetic ratings coefficients over the last three years compared to the

${ }^{22}$ http://www.sec.gov/rules/final/2010/33-9146.pdf. 
prior twelve years is highly significant (t-statistic of 8.6). A similar, although weaker (as expected) result is obtained when using the January 2011 cut - the t-statistic for the change in the average difference between the agency and synthetic ratings coefficients over the last six years compared to the prior nine years is 3.2 .

\section{Synthetic ratings and subsequent changes in agency ratings}

Because the synthetic ratings are estimated using agency ratings, it may appear surprising that synthetic ratings provide information about credit risk (as measured using the CDS variables) that is incremental to that in the agency ratings. However, the synthetic ratings also reflect the information contained in credit risk predictors (e.g. profitability, leverage), and that information may be reflected in agency ratings in an uneven way. For example, the agency ratings of large companies may reflect changes in leverage in a timely fashion, while the adjustment for small firms may be less timely. In addition, CRAs review and adjust their ratings on a periodic rather than continuous basis, and they make the adjustments at different times for different companies. Therefore, even if the agencies pay the same attention to all companies, at any point in time some ratings are timelier then others. And because they care about the stability of the ratings in addition to their informativeness (e.g., Lofflet, 2004; Altman and Rijken, 2004; Cantor and Mann, 2007), CRAs may ignore changes in the financial positions of some issuers if those changes are relatively small or are expected to reverse.

The extent to which agency ratings reflect credit-relevant information may vary across issuers also because of biases. CRAs may deliberately bias or delay downgrading the ratings of some issuers, fearing losing those issuers' business (e.g., Jiang, Stanford and Xie, 2013). In 
addition, agency ratings may reflect selection bias resulting from issuers' engaging in rating shopping, especially those that are rated by only one CRA (Kronlund, 2017).

Finally, while the synthetic ratings estimated in this study are based on easily available information, which CRAs likely consider when adjusting ratings, the calculation of the synthetic ratings involves a systematic fitting of ratings to their determinants across all rated companies. CRAs likely consider the relative credit quality of companies when adjusting ratings, but they may not do so as systematically as is done in this study (cross sectional ordered logit regressions with transformed variables, estimated across all rated companies).

If synthetic ratings indeed contain credit-related information that is not fully impounded in contemporaneous agency ratings, and over time CRAs adjust their ratings to better reflect credit risk, the difference between the synthetic and agency ratings should predict changes in agency ratings. To test this hypothesis, I run the following regressions

$$
\text { Rating }_{f}-\text { Rating }_{f-1}=\beta_{0}+\beta_{1}(\text { SRating }- \text { Rating })+\beta_{2} \text { Rating }+\varepsilon
$$

for $f=1,2, \ldots, 24$, where $f$ denotes a future month. Figure 5 plots the coefficient on the difference $\left(\beta_{1}\right)$. Results are presented when the regressions are estimated using all firms (Panel A) as well as for sub-samples partitioned based on period (Panel B) and firm size (Panel C). The regressions include Rating as a control variable to mitigate any bias from mean-reversion in agency ratings (e.g., Jorion and Zhang, 2007), but omitting this variable has little effect.

Panel A of Figure 5 shows that $\beta_{1}$, the coefficient on the difference between the synthetic and agency ratings of regression model (3), is positive in each of the subsequent 24 month. For month $f=1$, the coefficient is $1.3 \%$ and it declines monotonically to $0.5 \%$ in month $f=24$. Panel B plots the regression coefficients for three subsamples partitioned based on time period: From December 1985 through December 1999 (80s \& 90s), the 2000s, and the 2010s. The three plots 
are very similar, suggesting that the timeliness of agency ratings with respect to the information in synthetic ratings did not improve much over of the last thirty years.

Panel $\mathrm{C}$ of Figure 5 plots the regression coefficient for subsamples partitioned based on firm size (above and below the median market value of equity each month), while Panel D plots the cumulative coefficients by firm size. As shown, the coefficients are substantially larger for small companies, indicating that the agency ratings of small companies are less timely than those of large companies. This result is consistent with the conjecture that small companies receive less attention from CRAs. Two years after measuring the difference between the synthetic and agency ratings, agency ratings of small (large) firms close about $20 \%(15 \%)$ of this gap; that is, at least $20 \%(15 \%)$ of the initial difference between the synthetic and agency ratings is due to agency ratings failing to reflect the synthetic rating information. The remaining difference is due to measurement error in the synthetic ratings, and possibly to some remaining predictability (I examine convergence for only up to two years due to concerns about the increasing impact of survivorship and other selection biases).

To evaluate the statistical significance of the results shown in Figure 5, Table 5 presents summary statistics from the following regressions:

$$
\begin{aligned}
& \text { Rating }_{f}-\text { Rating }_{f-1} \\
& \quad=\beta_{0}+\beta_{1} \text { Small }+\beta_{2}(\text { SRating }- \text { Rating })+\beta_{3} \text { Small } \times(\text { SRating } \\
& - \text { Rating })+\beta_{4} \text { Rating }+\beta_{5} \text { Small } \times \text { Rating }+\varepsilon
\end{aligned}
$$

for $f=1,3,6,12,24$, where Small is a dummy variable that is equal one for firms with market value of equity below the median in that month. The results demonstrate the statistical significance of the patterns depicted in Figure 5. The t-statistics for the rating difference coefficients are highly 
significant throughout the 24 month period, and the t-statistics for the incremental effect for small firms are highly significant for at least six months.

\section{Market pricing of synthetic ratings}

Given the inefficiency of agency ratings with respect to the information provided by the synthetic ratings, and the role that ratings play in pricing CDS (e.g., Hull, Predescu and White, 2004; Micu, Remolona and Wooldridge, 2004), it is possible that CDS spreads are also inefficient with respect to the information in synthetic credit ratings. To test this hypothesis, I examine whether the difference between the synthetic and agency ratings predicts subsequent changes in CDS spreads. Specifically, I run the following regression models:

$$
\begin{aligned}
\text { CDS_Return }_{f} & =\beta_{0}+\beta_{1} \text { Small }+\beta_{2}(\text { SRating }- \text { Rating })+\beta_{3} \text { Small } \times(\text { SRating } \\
& - \text { Rating })+\beta_{4} \text { Rating }+\beta_{5} \text { Small } \times \text { Rating }+\varepsilon
\end{aligned}
$$

for $f=1,3,6,12,24$. I estimate CDS_Return as the median percentage change in CDS_Spread5 during month $f$ across the four types of credit events that trigger default swap contracts (see footnote 19). As shown in Panel A of Table 6, none of the explanatory variables predicts CDS returns. It appears that CDS investors recognize the inefficiencies of agency ratings and price the incremental information contained in the synthetic ratings in a timely fashion.

To the extent that credit-related information affects equity value (e.g., Holthausen and Leftwich, 1986), and equity investors do not fully price it (e.g., Campbell, Hilscher and Szilagyi, 2008), the difference between the synthetic and agency ratings may predict subsequent stock returns. To test this hypothesis, I substitute stock return in future month $f$ for CDS_Return $f$ and rerun Equation (5), including beta, size, and the book-to-market ratio as control variables. Again, I find that synthetic ratings do not predict market returns (Panel B of Table 6), suggesting that 
equity investors price the credit-related information contained in the synthetic ratings in a timely fashion. ${ }^{23}$ Results are similar when I use excess stock returns (stock return minus market return) instead of stock return, as well as when I use excess CDS return (CDS return minus its crosssection average across all firms) instead of the CDS return.

\section{Summary and conclusion}

This study develops and evaluates a model that generates synthetic credit ratings using accounting and market based information. The model performs very well in explaining agency ratings, suggesting that fitted values for unrated companies are likely to be reasonably precise. In addition, the synthetic ratings help explain cross sectional differences in CDS spreads, even after controlling for agency ratings. This result suggests that agency ratings do not fully impound the information in the synthetic ratings. Indeed, differences between the synthetic and agency ratings predict changes in agency ratings in subsequent months, especially for small companies. Investors, in contrast, appear to process the synthetic rating information in a timely fashion, as the difference between the synthetic and agency ratings does not predict changes in CDS spreads or in stock prices.

This study is obviously not the first to develop a model that uses financial statement information to predict credit ratings (prior studies are discussed in Section 2). In addition, studies going back to Altman (1968) have developed default prediction models, which are similar to rating

prediction models. This study contributes to the literature by making modelling improvements in

\footnotetext{
${ }^{23}$ Campbell, Hilscher and Szilagyi (2008) estimate a dynamic logit model with both accounting and equity market variables as explanatory variables for subsequent failure. They find that investors systematically underestimate the predictive information in their model, which is shown to predict future returns. This study focuses on explaining credit rating rather than failure, which likely explains the difference in results.
} 
generating synthetic credit ratings. More importantly, the study documents inefficiencies in agency ratings relative to synthetic ratings, and it provides evidence that the incremental information conveyed by agency ratings has declined substantially in recent years, possibly due to the effects of new SEC regulation that may limit the ability of CRAs to obtain confidential information from rated companies. The study further shows that investors are substantially more efficient than credit agencies in evaluating credit risk.

One implication of the results is that financial statement analysis provides information relevant for evaluating credit quality that is incremental to that in agency ratings. Another implication is that credit agencies should be able to quite easily improve the efficiency of their ratings, and if they do not do so they may risk losing their relevance over time. If the recent decline in the incremental information provided by agency ratings relative to synthetic ratings is indeed due to the removal from Regulation FD of the exemption for CRAs, then the likelihood that this trend will reverse is low. In addition, the secular positive trend in investors' ability to obtain and process financial information implies that investors' ability to generate timely synthetic ratings, which can be used as a substitute to agency ratings, will increase over time. Further contributing to the potential for CRAs to become less relevant are the recent regulatory changes that reduced regulatory reliance on agency ratings (e.g., Soroushian, 2016). 


\section{References}

Altman, E., 1968. Financial ratios, discriminant analysis and the prediction of corporate bankruptcy. The Journal of Finance 23(4), $589-609$.

Altman, E., Rijken, H., 2004. A point-in-time perspective on through-the-cycle ratings. Financial Analysts Journal 62(1), $54-70$.

Amato, J., Furfine, C., 2004. Are credit ratings procyclical? Journal of Banking \& Finance 28, 2641 2677.

Ashbaugh-Skaife, H., Collins, D., LaFond, R., 2006. The Effects of Corporate Governance on Firms Credit Ratings. Journal of Accounting and Economics 42, 203 - 243.

Bhojraj, S., Sengupta, P., 2003. Effect of Corporate Governance on Bond Ratings and Yields: The Role of Institutional Investors and Outside Directors. Journal of Business 76(3), $455-475$.

Blume, M., Lim, F., MacKinlay, A., 1998. Thee declining quality of US corporate debt: Myth or reality? Journal of Finance 53, $1389-1413$.

Bullard, M., 2016. Insider Trading in a Mannean Marketplace. Temple Law Review, 88, pp.223-383.

Cantor R, Mann C., 2007. Analyzing the tradeoff between ratings accuracy and stability. Journal of Fixed Income 16, 60-68.

Campbell, J.Y., Hilscher J., Szilagyi J., 2008. In Search of Distress Risk. Journal of Finance LXIII (6), 2899-2939.

Corrado, C.A., Hulten, C.R., 2010. How do you measure a technological revolution? American Economic Review, 100 (2), 99-104.

Dechow, P. M., Ge, W., 2006. The Persistence of Earnings and Cash Flows and the Role of Special Items: Implications for the Accrual Anomaly. Review of Accounting Studies 11, 253-296.

Ederington, L., 1985. Classification models and bond ratings. The Financial Review 20, $237-261$.

Fama, E.F., French, K.R., 2004. New lists: fundamentals and survival rates. Journal of Financial Economics, 73 (2), 229-269.

Givoly, D., Hayn, C., 2000. The Changing Time-Series Properties of Earnings, Cash Flows and Accruals: Has Financial Reporting Become More Conservative? Journal of Accounting and Economics 29, 287-320.

Holthausen, R., Leftwich, R., 1986. The effect of bond rating changes on common stock prices. The Journal Financial Economics 17, 57 - 89. 
Hull, J.C., Predescu, M., White, A.D., 2004. The relationship between credit default swap spreads, bond yields, and credit rating announcements. Journal of Banking and Finance 28, 2789-2811.

Jiang, J.X., Stanford, M.H. and Xie, Y., 2012. Does it matter who pays for bond ratings? Historical evidence. Journal of Financial Economics, 105(3), pp.607-621.

Jorion, P., Liu, Z., Shi, C., 2005. Informational effects of regulation FD: Evidence from rating agencies. Journal of Financial Economics 76, 309 - 330.

Jorion, P., Zhang, G., 2007. Information effects of bond rating changes: The role of the rating prior to the announcement. The Journal of Fixed Income 16(4), $45-59$.

Jorion, P., Shi, C., Zhang, S., 2009. Tightening credit standards: the role of accounting quality. Review of Accounting Studies 14, $123-160$.

Kaplan, R., Urwitz, G., 1979. Statistical models of bond ratings: A methodological inquiry. Journal of Business 52, $231-261$.

Katz, S., 1974. The price adjustment process of bonds to rating reclassification: A test of bond market efficiency. The Journal of Finance 29(2), $551-559$.

Kisgen, D., Strahan, P., 2010. Do regulations based on credit ratings affect a firm's cost of capital? The Review of Financial Studies 23, $4325-4347$.

Kothari, S., Laguerre, T., Leone, A., 2002. Capitalization versus expensing: Evidence on the uncertainty of future earnings from capital expenditures versus R\&D outlays. Review of Accounting Studies $7,355-382$.

Kronlund, Mathias, 2017. Do Bond Issuers Shop for Favorable Credit Ratings? Available at SSRN.

Lerman, A., Livnat, J., 2010. The New Form 8-K Disclosures. Review of Accounting Studies 15, 752778.

Löffler, G., 2004. An anatomy of rating through the cycle. Journal of Banking \& Finance, 28(3), pp.695720.

Longstaff, F.A., Mithal, S. and Neis, E., 2005. Corporate yield spreads: Default risk or liquidity? New evidence from the credit default swap market. The Journal of Finance, 60(5), pp.2213-2253.

Li, N., 2016. Performance Measures in Earnings-Based Financial Covenants in Debt Contracts. Journal of Accounting Research 54(4).

Manso, G., Strulovici, B., Tchistyi, A., 2010. Performance-Sensitive Debt. Review of Financial Studies 23 (5), 1819-1854.

Micu, M., Remolona, E., Wooldridge, P., 2004. The price impact of rating announcements: Evidence from the credit default swap market. BIS Quarterly Review June, 55 - 65. 
Merton, R., 1974. On the pricing of corporate debt: The risk structure of interest rates. Journal of Finance 29, 449-470.

Petersen, M.A., 2009. Estimating Standard Errors in Finance Panel Data Sets: Comparing Approaches. Review of Financial Studies 22, 435-480.

Pinches, G., Singleton, J., 1978. The adjustment of stock prices to bond rating changes. The Journal of Finance 33(1), $29-44$.

Soroushian, John. 2016. Credit Ratings in Financial Regulation: What's Changed Since the Dodd-Frank Act? Office of Financial Research Brief Series.

White, L.J., 2013. "Credit Rating Agencies: An Overview," Annual Review of Financial Economics 5, 93-122. 


\section{Table 1}

Frequency tables for agency ratings

Panel A: Letter rating (S\&P Domestic Long Term Issuer Credit Rating, Compustat's SPLTICRM)

\begin{tabular}{lrrr}
\hline & Frequency Count & Percent of Total Frequency & Cumulative Percent \\
\cline { 2 - 2 } AAA & 3,838 & $1.18 \%$ & $1.18 \%$ \\
AA+ & 1,663 & $0.51 \%$ & $1.69 \%$ \\
AA & 6,803 & $2.09 \%$ & $3.77 \%$ \\
AA- & 7,531 & $2.31 \%$ & $6.08 \%$ \\
A+ & 13,728 & $4.21 \%$ & $10.29 \%$ \\
A & 23,833 & $7.31 \%$ & $17.60 \%$ \\
A- & 19,937 & $6.12 \%$ & $23.72 \%$ \\
BBB+ & 25,046 & $7.68 \%$ & $31.40 \%$ \\
BBB & 35,382 & $10.85 \%$ & $42.25 \%$ \\
BBB- & 29,549 & $9.06 \%$ & $51.32 \%$ \\
BB+ & 22,847 & $7.01 \%$ & $58.32 \%$ \\
BB & 30,580 & $9.38 \%$ & $67.70 \%$ \\
BB- & 35,978 & $11.04 \%$ & $78.74 \%$ \\
B+ & 34,733 & $10.65 \%$ & $89.39 \%$ \\
B & 18,562 & $5.69 \%$ & $95.09 \%$ \\
B- & 9,011 & $2.76 \%$ & $97.85 \%$ \\
CCC+ & 3,075 & $0.94 \%$ & $98.79 \%$ \\
CCC & 1,509 & $0.46 \%$ & $99.26 \%$ \\
CCC- & 611 & $0.19 \%$ & $99.44 \%$ \\
CC & 507 & $0.16 \%$ & $99.60 \%$ \\
C & 6 & $0.00 \%$ & $99.60 \%$ \\
D & 1,305 & $0.40 \%$ & $100.00 \%$ \\
\hline Total non-missing & 326,034 & & \\
Missing & 748,567 & & \\
Total & $1,074,601$ & & \\
\hline & & & \\
\hline
\end{tabular}


Panel B: Numeric rating (Rating)

\begin{tabular}{lrrrr}
\hline & & \multicolumn{2}{c}{$\begin{array}{c}\text { Percent of Total } \\
\text { Frequency }\end{array}$} & Cumulative Percent \\
\cline { 2 - 3 } 1 (AAA) & Frequency Count & 3,838 & $1.18 \%$ & $1.18 \%$ \\
2 (AA) & 15,997 & $4.91 \%$ & $6.08 \%$ \\
3 (A) & 57,498 & $17.64 \%$ & $23.72 \%$ \\
4 (BBB) & 89,977 & $27.60 \%$ & $51.32 \%$ \\
5 (BB) & 89,405 & $27.42 \%$ & $78.74 \%$ \\
6 (B) & 62,306 & $19.11 \%$ & $97.85 \%$ \\
7 (CCC-D) & 7,013 & $2.15 \%$ & $100.00 \%$ \\
\hline Total non-missing & 326,034 & & \\
Missing & 748,567 & & \\
Total & $1,074,601$ & & \\
\hline
\end{tabular}

The sample includes monthly observations during the period December 1985 through January 2017. Letter rating is S\&P Domestic Long Term Issuer Credit Rating from Compustat (SPLTICRM). Numeric rating (Rating) is calculated as follow: SPLTICRM $=\mathrm{AAA} \Rightarrow$ Rating $=1$, SPLTICRM $=\mathrm{AA}+, \mathrm{AA}$, or AA- $\Rightarrow$ Rating $=2$, SPLTICRM $=\mathrm{A}+, \mathrm{A}$, or A- $\Rightarrow$ Rating $=$ 3, $\mathrm{SPLTICRM}=\mathrm{BBB}+, \mathrm{BBB}$, or $\mathrm{BBB}-\Rightarrow$ Rating $=4$, $\mathrm{SPLTICRM}=\mathrm{BB}+, \mathrm{BB}, \mathrm{BB}-\Rightarrow$ Rating $=5$, SPLTICRM $=\mathrm{B}+, \mathrm{B}, \mathrm{B}-$ $\Rightarrow$ Rating $=6$, and SPLTICRM $=\mathrm{CCC}+, \mathrm{CCC}, \mathrm{CCC}-, \mathrm{CC}, \mathrm{C}$, or $\mathrm{D} \Rightarrow$ Rating $=7$. 
Table 2

Summary statistics from cross-sectional ordinal logit regressions explaining agency ratings

$$
g(\operatorname{Pr}(\text { Rating } \leq i))=\alpha_{i}+\beta_{1} \log \left(M_{-} E B I T D A\right)+\beta_{2} \log (\text { Interest })+\beta_{3} \log (D \& A)+\beta_{4} \text { TangLev }+\beta_{5} \log (\text { MVEquity })+\beta_{6} \text { RetVolat }
$$

for $i=1,2, \ldots, 6$

\begin{tabular}{|c|c|c|c|c|c|c|c|c|c|c|c|c|c|c|}
\hline & $\alpha_{1}$ & $\alpha_{2}$ & $\alpha_{3}$ & $\alpha_{4}$ & $\alpha_{5}$ & $\alpha_{6}$ & $\beta_{1}$ & $\beta_{2}$ & $\beta_{3}$ & $\beta_{4}$ & $\beta_{5}$ & $\beta 6$ & Mean $\mathrm{R}^{2}$ & Mean Obs. \\
\hline mean(coef.) & -15.028 & -12.425 & $\overline{-9.336}$ & $\overline{-6.415}$ & $\overline{-3.194}$ & $\overline{2.485}$ & $\overline{1.071}$ & $\overline{-0.689}$ & $\overline{-0.293}$ & $\overline{-0.705}$ & $\overline{1.084}$ & $\overline{-28.063}$ & 0.742 & 870 \\
\hline $\mathrm{t}($ mean $($ coef. $))$ & -79.4 & -68.6 & -53.8 & -42.0 & -22.3 & 19.2 & 74.9 & -87.3 & -29.3 & -28.5 & 101.7 & -71.3 & & \\
\hline $\operatorname{median}(z($ coef. $))$ & -17.4 & -17.2 & -14.4 & -9.9 & -3.8 & 3.9 & 7.5 & -8.3 & -2.8 & -2.9 & 10.9 & -11.1 & & \\
\hline \multicolumn{7}{|c|}{ mean $($ coef. $\times$ std(exp. variable $))$} & 1.711 & -1.012 & -0.471 & -0.259 & 1.912 & -1.349 & & \\
\hline \multicolumn{7}{|c|}{ median $($ coef. $\times$ std $($ exp. variable $))$} & 1.765 & -0.961 & -0.501 & -0.236 & 1.893 & -1.422 & & \\
\hline
\end{tabular}

The sample includes monthly observations during the period December 1985 through January 2017 (374 cross-sectional regressions). g(.) is the logit function. mean(coef.) is the timeseries mean of the corresponding coefficient from the monthly ordinal logit regressions. $t$ (mean(coef.)) is the t-statistic of the mean coefficient (the ratio of the time-series mean to its standard error). median(z(coef.)) is the time-series median of the regression $z$-statistic. coef. $\times$ std(explanatory variable) is a measure of the economic significance of the explanatory variable (explained in Section 3). The variables are measured using the most recently available information as of the end of each month. $\boldsymbol{M}_{-} \boldsymbol{E B I T D A}$ is the median value of EBITDA (Compustat's OIBDP) over the last three fiscal years; Interest is interest cost (interest expense plus capitalized interest, Compustat's XINT) over the most recent four quarters or the most recent annual report if the trailing four quarter value is missing; $\boldsymbol{D} \boldsymbol{\&} \boldsymbol{A}$ is depreciation and amortization (Compustat's DP) over the most recent four quarters or the most recent annual report if the trailing four quarter value is missing; TangLev is tangible leverage, measured as the ratio of total liabilities (Compustat's LT) to the book value tangible assets (total assets minus intangible assets, Compustat's AT - INTAN) as of the most recent quarter or the most recent annual report if quarterly INTAN is missing; MVEquity is the market value of common equity at the end of the month; RetVolat is return volatility, estimated using the 60 most recent monthly stock returns through the end of the month (a minimum of 30 observations is required). Rating is a numeric measure of credit rating, calculated as follow: S\&P Domestic Long Term Issuer Credit Rating (Compustat's SPLTICRM) $=$ AAA $\Rightarrow$ Rating $=1$, SPLTICRM $=\mathrm{AA}+, \mathrm{AA}$, or AA- $\Rightarrow$ Rating $=2$, SPLTICRM $=\mathrm{A}+, \mathrm{A}$, or A- $\Rightarrow$ Rating $=3$, SPLTICRM $=\mathrm{BBB}+$, BBB, or BBB- $\Rightarrow$ Rating $=4, \mathrm{SPLTICRM}=\mathrm{BB}+$, BB, BB- $\Rightarrow$ Rating $=5$, SPLTICRM $=\mathrm{B}+, \mathrm{B}, \mathrm{B}-\Rightarrow$ Rating $=6$, and SPLTICRM $=\mathrm{CCC}+\mathrm{CCC}, \mathrm{CCC}-, \mathrm{CC}, \mathrm{C}$, or $\mathrm{D} \Rightarrow$ Rating $=7$. 
Table 3

Accuracy of synthetic credit rating

\begin{tabular}{|c|c|c|c|}
\hline $\begin{array}{l}\text { Synthetic } \\
\text { rating }\end{array}$ & Rating & $\begin{array}{l}\text { Frequency } \\
\text { count }\end{array}$ & $\begin{array}{l}\text { Percent of total } \\
\text { frequency }\end{array}$ \\
\hline 1 & 1 & 825 & $69.8 \%$ \\
\hline 1 & 2 & 278 & $23.5 \%$ \\
\hline 1 & 3 & 79 & $6.7 \%$ \\
\hline 2 & 1 & 2,394 & $22.1 \%$ \\
\hline 2 & 2 & 5,536 & $51.2 \%$ \\
\hline 2 & 3 & 2,620 & $24.2 \%$ \\
\hline 2 & 4 & 260 & $2.4 \%$ \\
\hline 2 & 5 & 2 & $0.0 \%$ \\
\hline 2 & 7 & 6 & $0.1 \%$ \\
\hline 3 & 1 & 567 & $1.0 \%$ \\
\hline 3 & 2 & 9,730 & $16.5 \%$ \\
\hline 3 & 3 & 34,403 & $58.4 \%$ \\
\hline 3 & 4 & 13,256 & $22.5 \%$ \\
\hline 3 & 5 & 938 & $1.6 \%$ \\
\hline 3 & 6 & 44 & $0.1 \%$ \\
\hline 3 & 7 & 6 & $0.0 \%$ \\
\hline 4 & 1 & 51 & $0.1 \%$ \\
\hline 4 & 2 & 434 & $0.4 \%$ \\
\hline 4 & 3 & 19,608 & $19.7 \%$ \\
\hline 4 & 4 & 58,968 & $59.2 \%$ \\
\hline 4 & 5 & 18,877 & $19.0 \%$ \\
\hline 4 & 6 & 1,471 & $1.5 \%$ \\
\hline 4 & 7 & 132 & $0.1 \%$ \\
\hline 5 & 1 & 1 & $0.0 \%$ \\
\hline 5 & 2 & 18 & $0.0 \%$ \\
\hline 5 & 3 & 566 & $0.6 \%$ \\
\hline 5 & 4 & 16,494 & $18.1 \%$ \\
\hline 5 & 5 & 55,968 & $61.4 \%$ \\
\hline 5 & 6 & 17,800 & $19.5 \%$ \\
\hline 5 & 7 & 376 & $0.4 \%$ \\
\hline 6 & 3 & 45 & $0.1 \%$ \\
\hline 6 & 4 & 497 & $0.9 \%$ \\
\hline 6 & 5 & 13,101 & $22.6 \%$ \\
\hline 6 & 6 & 40,337 & $69.5 \%$ \\
\hline 6 & 7 & 4,050 & $7.0 \%$ \\
\hline 7 & 3 & 1 & $0.0 \%$ \\
\hline 7 & 4 & 16 & $0.3 \%$ \\
\hline 7 & 5 & 195 & $4.1 \%$ \\
\hline 7 & 6 & 2,277 & $47.5 \%$ \\
\hline 7 & 7 & 2,306 & $48.1 \%$ \\
\hline
\end{tabular}

The sample includes monthly observations during the period December 1985 through January 2017. Rating is a numeric measure of credit rating, calculated as follow: $\mathrm{SPLTICRM}=\mathrm{AAA} \Rightarrow$ Rating $=1$, SPLTICRM $=\mathrm{AA}+, \mathrm{AA}$, or AA- $\Rightarrow$ Rating $=2, \mathrm{SPLTICRM}=\mathrm{A}+, \mathrm{A}$, or A- $\Rightarrow$ Rating $=3, \mathrm{SPLTICRM}=\mathrm{BBB}+, \mathrm{BBB}$, or BBB$-\Rightarrow$ Rating $=4, \mathrm{SPLTICRM}=\mathrm{BB}+, \mathrm{BB}$, $\mathrm{BB}-\Rightarrow$ Rating $=5$, SPLTICRM $=\mathrm{B}+, \mathrm{B}, \mathrm{B}-\Rightarrow$ Rating $=6$, and SPLTICRM $=\mathrm{CCC}+, \mathrm{CCC}, \mathrm{CCC}-\mathrm{CC}, \mathrm{C}$, or D $\Rightarrow$ Rating $=$ 7, where SPLTICRM is S\&P Domestic Long Term Issuer Credit Rating (from Compustat). Synthetic rating is the fitted value from the regressions presented in Table 2. 
Table 4

\section{CDS spreads and credit ratings}

$$
\text { CDS }=\beta_{0}+\beta_{1} \text { Rating }+\beta_{2} \text { SRating }+\varepsilon
$$

Panel A: $C D S=C D S \_S p r e a d 5$

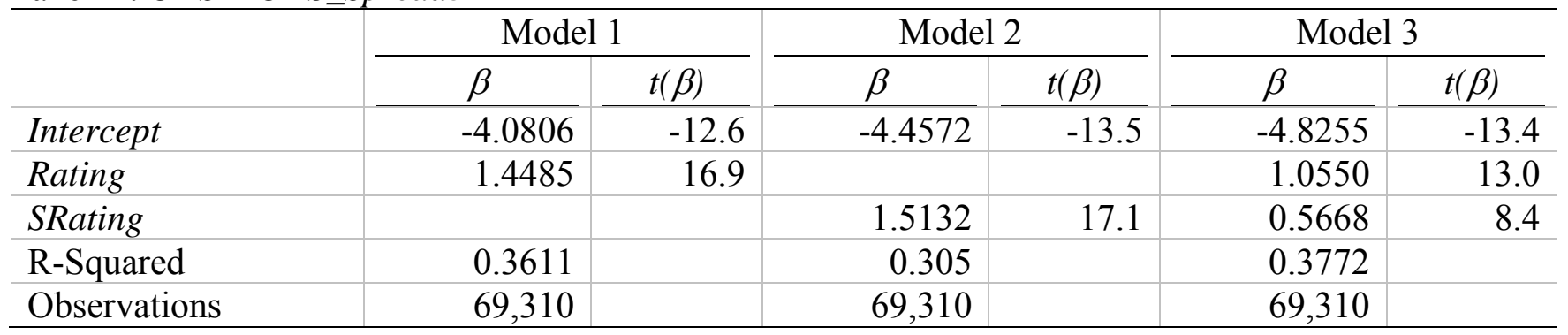

Panel B: $C D S=$ Excess $C D S \_$Spread5

\begin{tabular}{|c|c|c|c|c|c|c|}
\hline & \multicolumn{2}{|c|}{ Model 1} & \multicolumn{2}{|c|}{ Model 2} & \multicolumn{2}{|c|}{ Model 3} \\
\hline & $\beta$ & $t(\beta)$ & $\beta$ & $t(\beta)$ & $\beta$ & $t(\beta)$ \\
\hline Intercept & -5.8567 & -17.6 & -6.214 & -18.4 & -6.5827 & -17.8 \\
\hline Rating & 1.4398 & 16.9 & & & 1.0563 & 13.0 \\
\hline SRating & & & 1.5 & 17.2 & 0.5524 & 8.2 \\
\hline R-Squared & 0.377 & & 0.3167 & & 0.3932 & \\
\hline Observations & 69,310 & & 69,310 & & 69,310 & \\
\hline
\end{tabular}

Panel C: $C D S=$ CDS implied rating

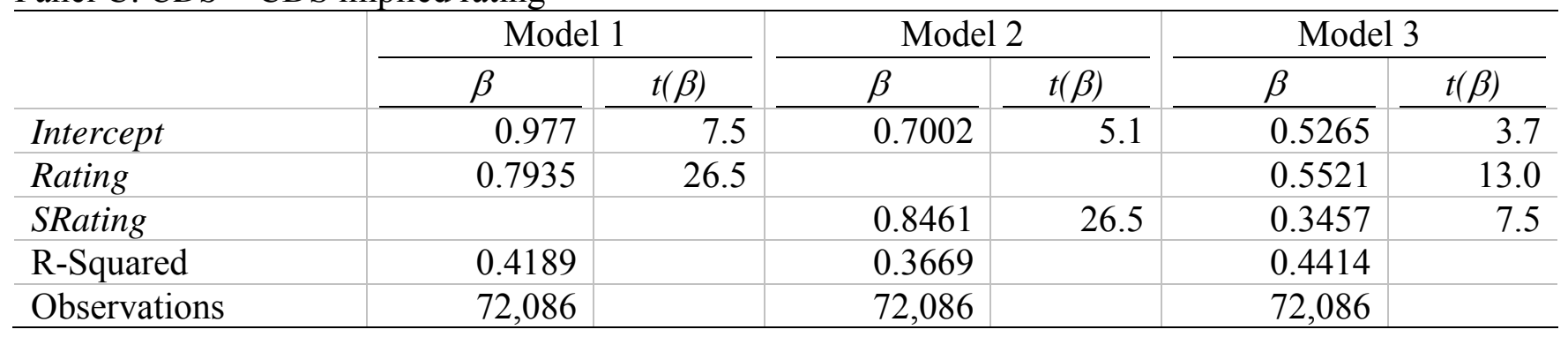

The sample includes monthly observations during the period January 2002 through January 2017. The t-statistics are calculated using two-ways (firm and time) clustered standard errors (Petersen 2009). CDS_Spread5 is the amount paid by the protection buyer to the protection seller in a five year contract, measured in annualized percentage points. Excess

CDS_Spread5 is the difference between CDS_Spread5 and its cross-section average across all firms. CDS Implied Rating is calculated by Markit "by comparing the issuer's five year senior standard trading convention spread to the five years spreads of the sector curves and applying the rating of the logarithmically nearest rating curve specific to that sector." The letter ratings are converted to a numerical scale using the same approached used to convert the agency ratings. Rating is a numeric measure of credit rating, calculated as follow: $\mathrm{SPLTICRM}=\mathrm{AAA} \Rightarrow$ Rating $=1$, SPLTICRM $=\mathrm{AA}+$, AA, or AA- $\Rightarrow$ Rating $=2$, SPLTICRM $=\mathrm{A}+, \mathrm{A}$, or A- $\Rightarrow$ Rating $=3$, SPLTICRM $=\mathrm{BBB}+, \mathrm{BBB}$, or BBB- $\Rightarrow$ Rating $=4$, SPLTICRM $=\mathrm{BB}+, \mathrm{BB}$, $\mathrm{BB}-\Rightarrow$ Rating $=5$, SPLTICRM $=\mathrm{B}+, \mathrm{B}, \mathrm{B}-\Rightarrow$ Rating $=6$, and SPLTICRM $=\mathrm{CCC}+, \mathrm{CCC}, \mathrm{CCC}-, \mathrm{CC}, \mathrm{C}$, or $\mathrm{D} \Rightarrow$ Rating $=$ 7, where SPLTICRM is S\&P Domestic Long Term Issuer Credit Rating (from Compustat). Synthetic rating (SRating) is the fitted value from the regressions presented in Table 2. 


\section{Table 5 \\ Predicting rating changes}

$$
\begin{aligned}
& \text { Rating }_{f}-\text { Rating }_{f-1} \\
& \quad=\beta_{0}+\beta_{1} \text { Small }+\beta_{2}(\text { SRating }- \text { Rating })+\beta_{3} \text { Small } \times(\text { SRating } \\
& - \text { Rating })+\beta_{4} \text { Rating }+\beta_{5} \text { Small } \times \text { Rating }+\varepsilon
\end{aligned}
$$

\begin{tabular}{|c|c|c|c|c|c|c|c|c|c|c|}
\hline & \multicolumn{2}{|c|}{$f=1$} & \multicolumn{2}{|c|}{$f=3$} & \multicolumn{2}{|c|}{$f=6$} & \multicolumn{2}{|c|}{$f=12$} & \multicolumn{2}{|c|}{$f=24$} \\
\hline & $\beta$ & $t(\beta)$ & $\beta$ & $t(\beta)$ & $\beta$ & $t(\beta)$ & $\beta$ & $t(\beta)$ & $\beta$ & $t(\beta)$ \\
\hline Intercept & 0.0105 & 7.5 & 0.0108 & 7.5 & 0.0102 & 7.5 & 0.0101 & 7.6 & 0.0108 & 8.1 \\
\hline Small & -0.0075 & -2.6 & -0.0037 & -1.3 & 0.0016 & 0.6 & 0.0078 & 2.8 & 0.0077 & 2.8 \\
\hline SRating - Rating & 0.0082 & 13.4 & 0.0078 & 13.2 & 0.0074 & 12.9 & 0.0064 & 11.1 & 0.004 & 6.9 \\
\hline Rating - Ratin & 0.0072 & 6.8 & 0.0054 & 5.5 & 0.003 & 3.5 & 0.0009 & 1.1 & 0.0004 & 0.5 \\
\hline Rating & -0.0026 & -6.8 & -0.0026 & -6.7 & -0.0023 & -6.2 & -0.0022 & -5.9 & -0.0022 & -5.7 \\
\hline Small $\times$ Rating & 0.0029 & 4.7 & 0.0021 & 3.4 & 0.0009 & 1.5 & -0.0006 & -1 & -0.001 & -1.6 \\
\hline R-Squared & 0.0065 & & 0.0055 & & 0.0043 & & 0.0032 & & 0.0019 & \\
\hline Observations & 318,939 & & 309,197 & & 297,772 & & 276,491 & & 239,628 & \\
\hline
\end{tabular}

The sample includes monthly observations during the period December 1985 through January 2017. The t-statistics are calculated using two-ways (firm and time) clustered standard errors (Petersen 2009). $\boldsymbol{f}$ denotes a future month. Small is a dummy variable that is equal one for firm with market value of equity below the median in that month. Rating is a numeric measure of credit rating, calculated as follow: $\mathrm{SPLTICRM}=\mathrm{AAA} \Rightarrow$ Rating $=1$, SPLTICRM $=\mathrm{AA}+$, AA, or AA- $\Rightarrow$ Rating $=2, \mathrm{SPLTICRM}=\mathrm{A}+, \mathrm{A}$, or A- $\Rightarrow$ Rating $=3, \mathrm{SPLTICRM}=\mathrm{BBB}+, \mathrm{BBB}$, or BBB- $\Rightarrow$ Rating $=4$, SPLTICRM $=\mathrm{BB}+, \mathrm{BB}$, BB- $\Rightarrow$ Rating $=5$, SPLTICRM $=\mathrm{B}+, \mathrm{B}, \mathrm{B}-\Rightarrow$ Rating $=6$, and SPLTICRM $=\mathrm{CCC}+, \mathrm{CCC}, \mathrm{CCC}-, \mathrm{CC}, \mathrm{C}$, or D $\Rightarrow$ Rating $=$ 7, where SPLTICRM is S\&P Domestic Long Term Issuer Credit Rating (from Compustat). Synthetic rating (SRating) is the fitted value from the regressions presented in Table 2 
Table 6

Predicting returns

$$
\begin{gathered}
\text { Return }_{f}=\beta_{0}+\beta_{1} \text { Small }+\beta_{2}(\text { SRating }- \text { Rating })+\beta_{3} \text { Small } \times(\text { SRating }- \text { Rating }) \\
+\beta_{4} \text { Rating }+\beta_{5} \text { Small } \times \text { Rating }+\varepsilon
\end{gathered}
$$

\begin{tabular}{|c|c|c|c|c|c|c|c|c|c|c|}
\hline & \multicolumn{2}{|c|}{$f=1$} & \multicolumn{2}{|c|}{$f=3$} & \multicolumn{2}{|c|}{$f=6$} & \multicolumn{2}{|c|}{$f=12$} & \multicolumn{2}{|c|}{$f=24$} \\
\hline & $\beta$ & $t(\beta)$ & $\beta$ & $t(\beta)$ & $\beta$ & $t(\beta)$ & $\beta$ & $t(\beta)$ & $\beta$ & $t(\beta)$ \\
\hline Intercept & 0.0254 & $\overline{2.2}$ & 0.0217 & $\overline{1.9}$ & 0.021 & $\overline{1.9}$ & 0.0221 & $\overline{1.8}$ & 0.0258 & 2.1 \\
\hline Small & -0.002 & -0.1 & 0.0081 & 0.4 & 0.0058 & 0.3 & 0.0067 & 0.4 & 0.0016 & 0.1 \\
\hline SRating - Rating & -0.0001 & 0.0 & -0.0002 & -0.1 & -0.0001 & -0.1 & -0.0005 & -0.2 & -0.0026 & -1.2 \\
\hline Small $\times($ SRating - Rating $)$ & -0.0026 & -0.6 & -0.0037 & -0.8 & -0.0037 & -0.8 & -0.0036 & -0.7 & -0.0037 & -0.8 \\
\hline Rating & -0.0031 & -1.6 & -0.002 & -1.0 & -0.0017 & -0.9 & -0.002 & -1.0 & -0.0029 & -1.4 \\
\hline Small $\times$ Rating & 0.0018 & 0.5 & -0.001 & -0.3 & -0.0009 & -0.2 & -0.0009 & -0.2 & 0.0002 & 0.1 \\
\hline R-Squared & 0.0002 & & 0.0001 & & 0.0001 & & 0.0001 & & 0.0002 & \\
\hline Observations & 65,868 & & 64,948 & & 64,483 & & 63,539 & & 61,501 & \\
\hline
\end{tabular}

Panel A: Return $=$ CDS return

\begin{tabular}{|c|c|c|c|c|c|c|c|c|c|c|}
\hline & \multicolumn{2}{|c|}{$f=1$} & \multicolumn{2}{|c|}{$f=3$} & \multicolumn{2}{|c|}{$f=6$} & \multicolumn{2}{|c|}{$f=12$} & \multicolumn{2}{|c|}{$f=24$} \\
\hline & $\beta$ & $t(\beta)$ & $\beta$ & $t(\beta)$ & $\beta$ & $t(\beta)$ & $\beta$ & $t(\beta)$ & $\beta$ & $t(\beta)$ \\
\hline Intercept & 0.0348 & 1.6 & 0.0365 & 1.6 & 0.0342 & $\overline{1.4}$ & 0.0317 & 1.2 & 0.0253 & $\overline{1.0}$ \\
\hline Small & 0.0059 & 0.9 & 0.0038 & 0.6 & 0.0008 & 0.1 & 0.0036 & 0.5 & 0.0056 & 1.0 \\
\hline SRating - Rating & -0.0026 & -1.4 & -0.0024 & -1.2 & -0.0023 & -1.1 & -0.0011 & -0.5 & 0.0004 & 0.2 \\
\hline Small $\times($ SRating - Rating $)$ & 0.0020 & 1.5 & 0.0014 & 1.0 & 0.0021 & 1.5 & 0.0004 & 0.3 & -0.0008 & -0.6 \\
\hline Rating & -0.0032 & -1.5 & -0.0033 & -1.5 & -0.0031 & -1.3 & -0.0022 & -0.9 & -0.001 & -0.4 \\
\hline Small $\times$ Rating & -0.0012 & -0.9 & -0.0009 & -0.7 & -0.0002 & -0.2 & -0.0009 & -0.7 & -0.0015 & -1.2 \\
\hline Beta & 0.0027 & 1.3 & 0.0028 & 1.3 & 0.002 & 1.0 & 0.0007 & 0.4 & 0.0007 & 0.4 \\
\hline Size & -0.0018 & -1.1 & -0.002 & -1.2 & -0.0018 & -1.0 & -0.0017 & -0.9 & -0.0014 & -0.8 \\
\hline$B / M$ & 0.0004 & 0.2 & 0.0006 & 0.2 & 0.0016 & 0.7 & 0.0019 & 1.2 & 0.0024 & 1.7 \\
\hline $\mathrm{R}-\mathrm{Squ}$ & 0.0006 & & 0.0006 & & 0.0005 & & 0.0005 & & 0.0004 & \\
\hline Observations & 312,192 & & 302,993 & & 291,989 & & 271,293 & & 235,197 & \\
\hline
\end{tabular}

Panel B: Return $=$ Stock return

For Panel A, the sample includes monthly observations during the period December 1985 through January 2017. The tstatistics are calculated using two-ways (firm and time) clustered standard errors (Petersen 2009). For Panel B, the sample starts in January 2002. CDS return as the median percentage change in CDS_Spread5 during future month $\boldsymbol{f}$ across the four types of credit events that trigger default swap contracts. Stock return is the stock return during future month $\boldsymbol{f}$. Small is a dummy variable that is equal one for firm with market value of equity below the median in that month. Rating is a numeric measure of credit rating, calculated as follow: $\mathrm{SPLTICRM}=\mathrm{AAA} \Rightarrow$ Rating $=1$, SPLTICRM $=\mathrm{AA}+, \mathrm{AA}$, or AA- $\Rightarrow$ Rating $=2$, $\mathrm{SPLTICRM}=\mathrm{A}+, \mathrm{A}$, or $\mathrm{A}-\Rightarrow$ Rating $=3$, $\mathrm{SPLTICRM}=\mathrm{BBB}+, \mathrm{BBB}$, or $\mathrm{BBB}-\Rightarrow$ Rating $=4$, $\mathrm{SPLTICRM}=\mathrm{BB}+, \mathrm{BB}$, $\mathrm{BB}-\Rightarrow$ Rating $=5$, SPLTICRM $=\mathrm{B}+, \mathrm{B}, \mathrm{B}-\Rightarrow$ Rating $=6$, and SPLTICRM $=\mathrm{CCC}+, \mathrm{CCC}, \mathrm{CCC}-, \mathrm{CC}, \mathrm{C}$, or $\mathrm{D} \Rightarrow$ Rating $=$ 7, where SPLTICRM is S\&P Domestic Long Term Issuer Credit Rating (from Compustat). Synthetic rating (SRating) is the fitted value from the regressions presented in Table 2. Beta is estimated using a time series regression of monthly stock returns over the 60 month period that ends in the current month on the S\&P 500 total return index (a minimum of 30 observations is required). Size is the log of the market value of equity at the end of the month. $\mathbf{B} / \mathbf{M}$ is the book-to-market ratio at the end of the month. 
Figure 1: R-squared and \# of observations over time from the credit rating model

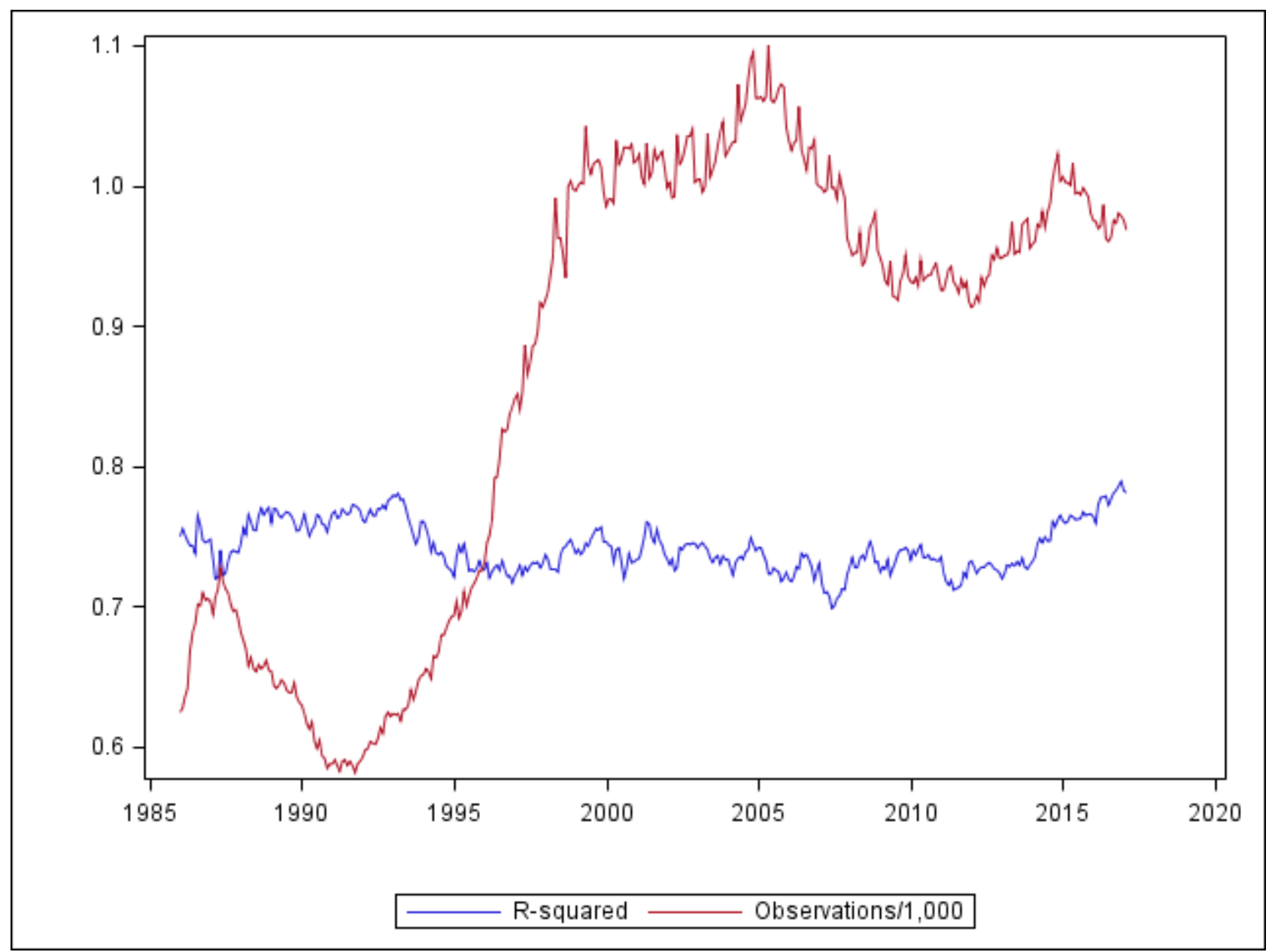

The figure plots the R-squared and number of observations (in thousands) from the cross-sectional monthly ordered logit regressions (Equation (1)). The model and variables are described in Section 2 and in the notes to Table 2. The sample covers the period December 1985 through January 2017. 
Figure 2: Statistical significance of the explanatory variables for credit rating over time

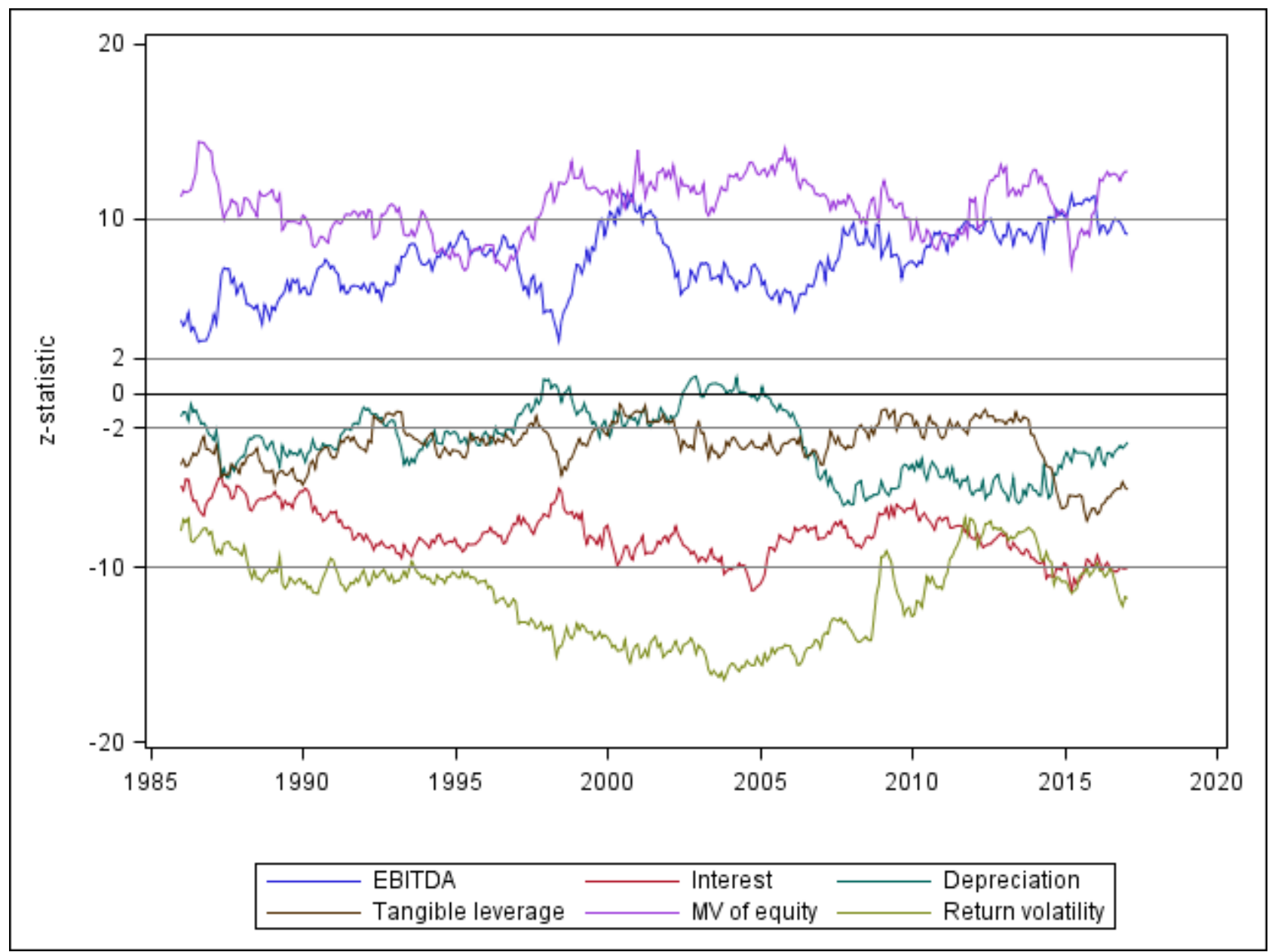

The figure plots the z-statistics of the coefficients from cross-sectional monthly ordered logit regressions (Equation (1)). The model and variables are described in Section 2 and in the notes to Table 2. The sample covers the period December 1985 through January 2017. 
Figure 3: Economic significance of the explanatory variables for credit rating over time

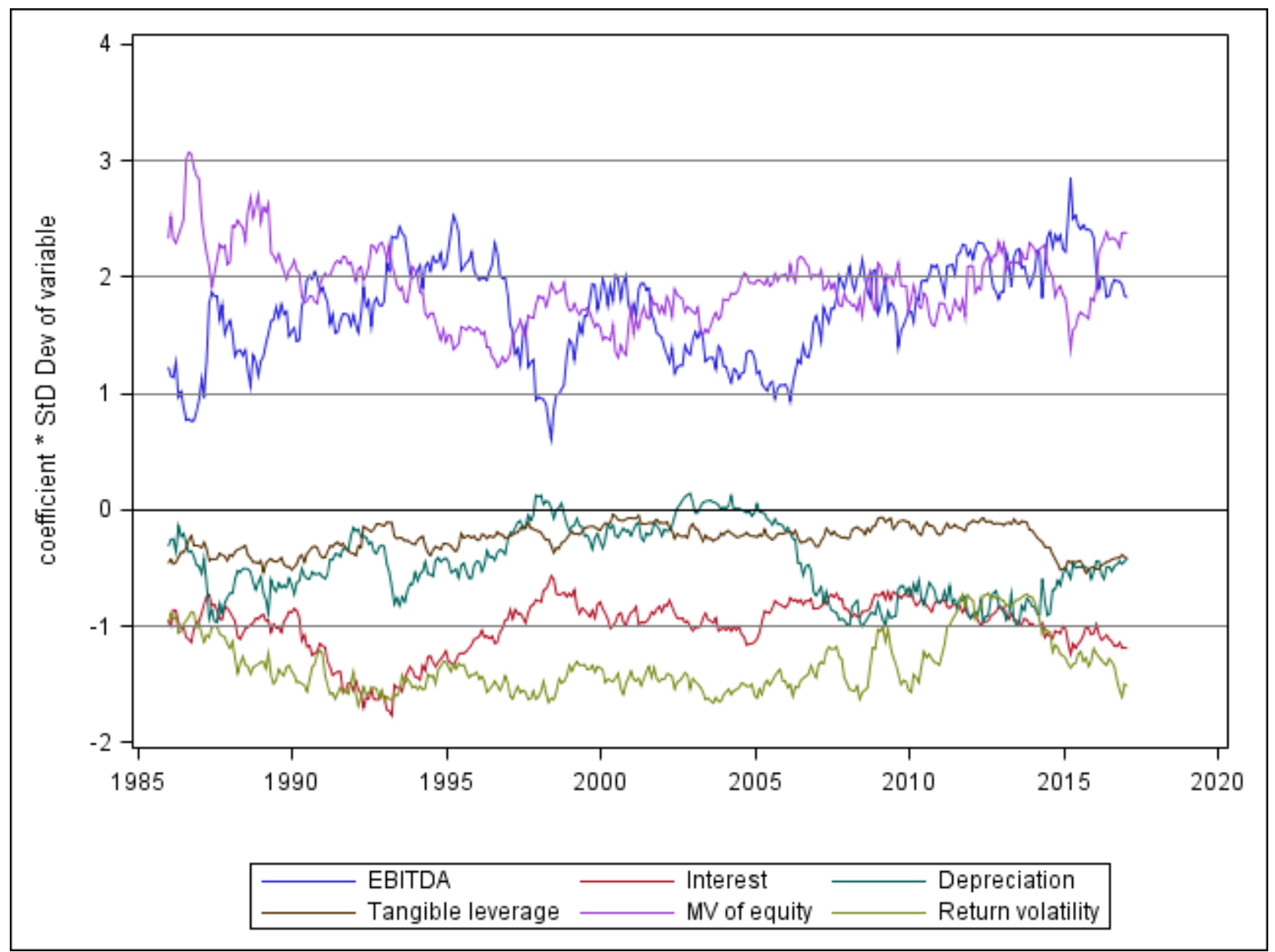

The figure plots measures of the economic significance of the explanatory variables (coef. $\times$ std(explanatory variable)) from cross-sectional monthly ordered logit regressions (Equation (1)). The model and variables are described in Section 2 and in the notes to Table 2. The sample covers the period December 1985 through January 2017. 
Figure 4: Coefficients from regressions of CDS spread on agency and synthetic ratings over time

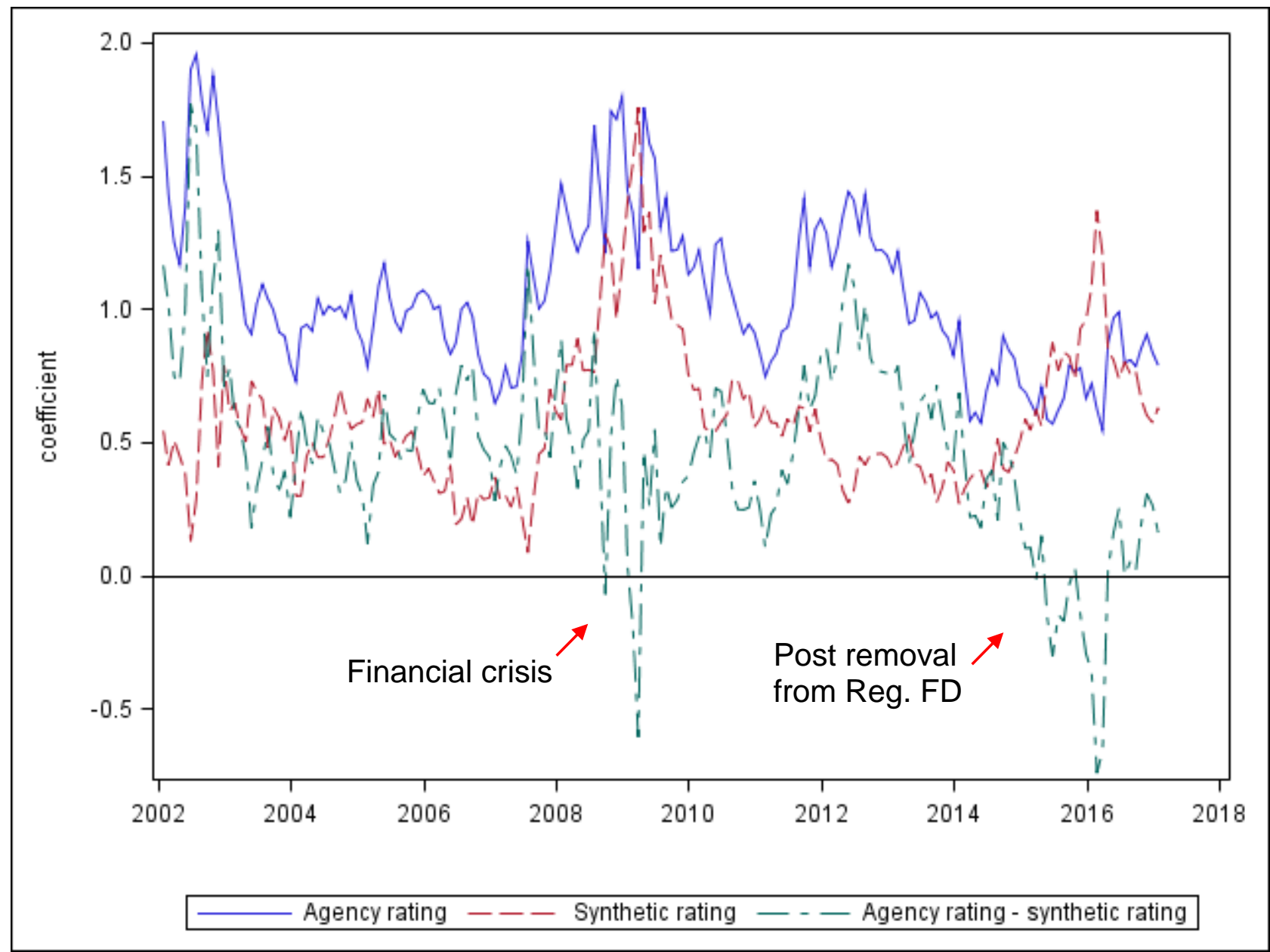

The figure plots the coefficients of agency rating (Rating) and synthetic rating (SRating) from cross sectional estimation of the following regression for each month during the period January 2002 through January 2017 (181 months): $C D S=\beta_{0}+$ $\beta_{1}$ Rating $+\beta_{2}$ SRating $+\varepsilon$ where CDS_Spread5 is the amount paid by the protection buyer to the protection seller in a five year contract, measured in annualized percentage points. Rating is a numeric measure of credit rating, calculated as follow: $\mathrm{SPLTICRM}=\mathrm{AAA} \Rightarrow$ Rating $=1$, SPLTICRM $=\mathrm{AA}+, \mathrm{AA}$, or AA- $\Rightarrow$ Rating $=2$, SPLTICRM $=\mathrm{A}+, \mathrm{A}$, or A- $\Rightarrow$ Rating $=$ 3, $\mathrm{SPLTICRM}=\mathrm{BBB}+, \mathrm{BBB}$, or BBB- $\Rightarrow$ Rating $=4$, SPLTICRM $=\mathrm{BB}+, \mathrm{BB}, \mathrm{BB}-\Rightarrow$ Rating $=5$, SPLTICRM $=\mathrm{B}+, \mathrm{B}, \mathrm{B}-$ $\Rightarrow$ Rating $=6$, and SPLTICRM $=\mathrm{CCC}+, \mathrm{CCC}, \mathrm{CCC}-, \mathrm{CC}, \mathrm{C}$, or $\mathrm{D} \Rightarrow$ Rating $=7$, where SPLTICRM is S\&P Domestic Long Term Issuer Credit Rating (from Compustat). Synthetic rating (SRating) is the fitted value from the regressions presented in Table 2. 
Figure 5: Predicting rating changes

\section{Panel A: All firms}

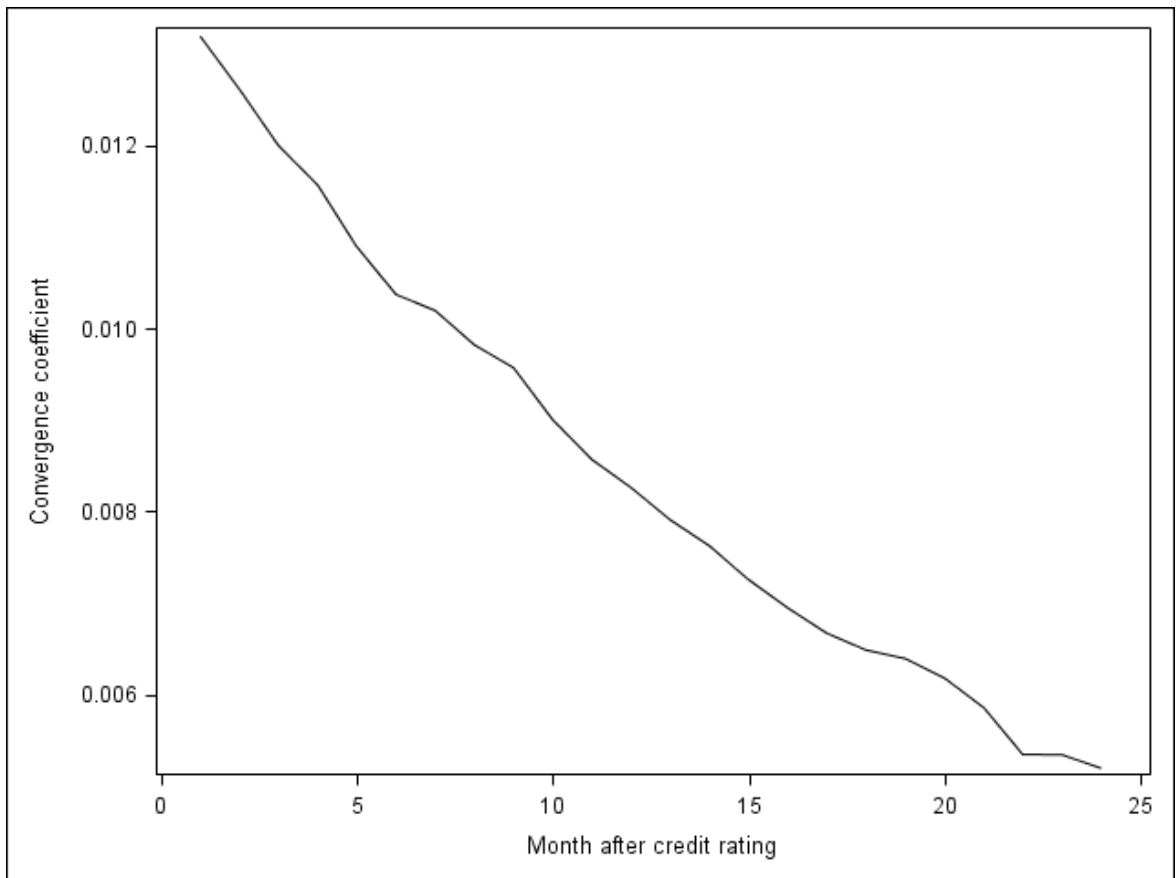

Panel B: By time period

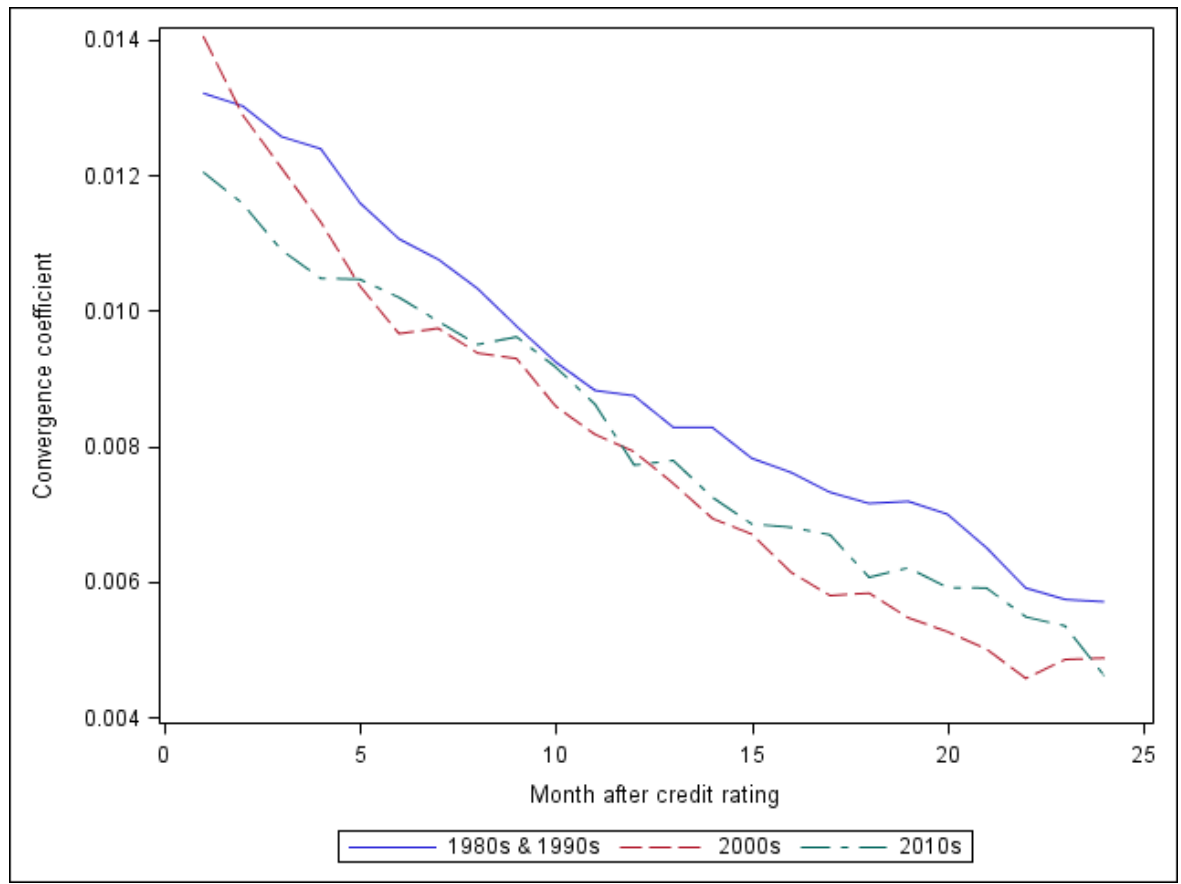




\section{Panel C: By size}

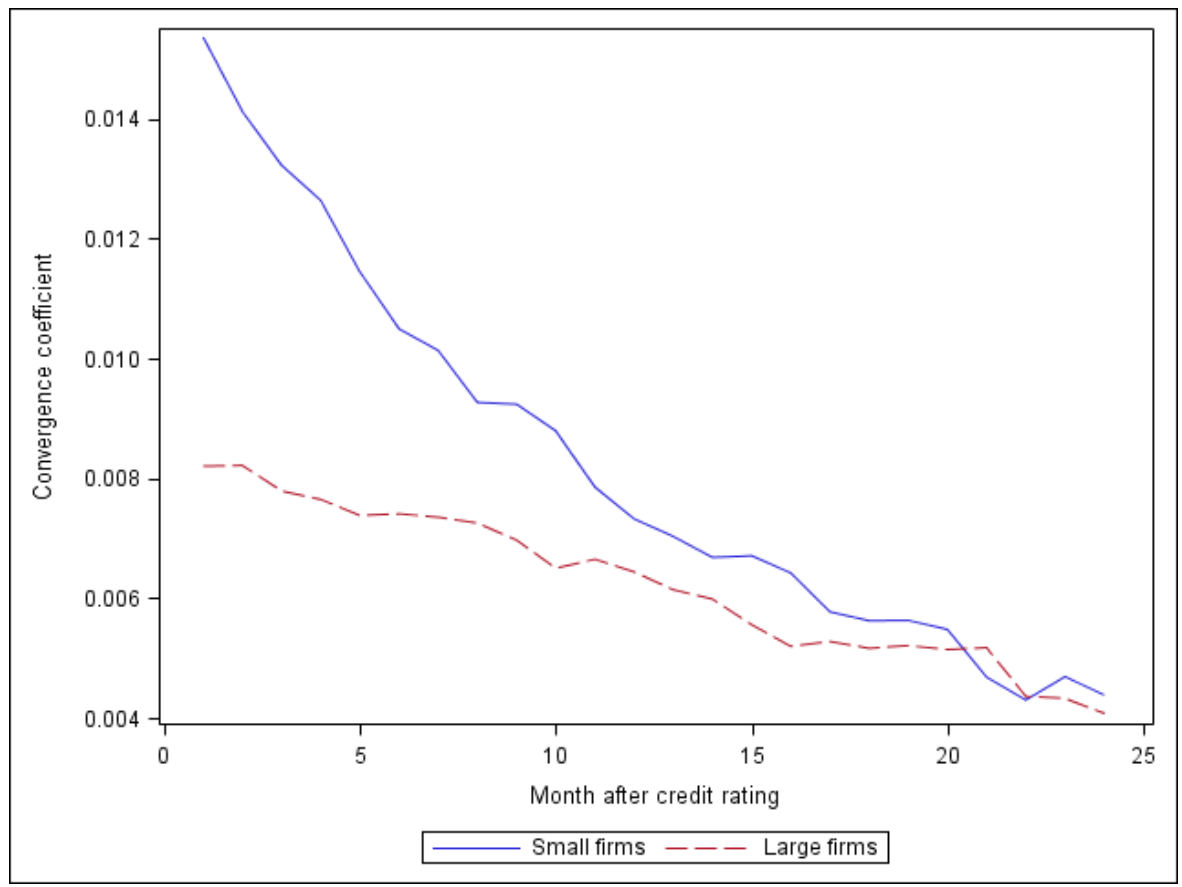

Panel D: Cumulative by size

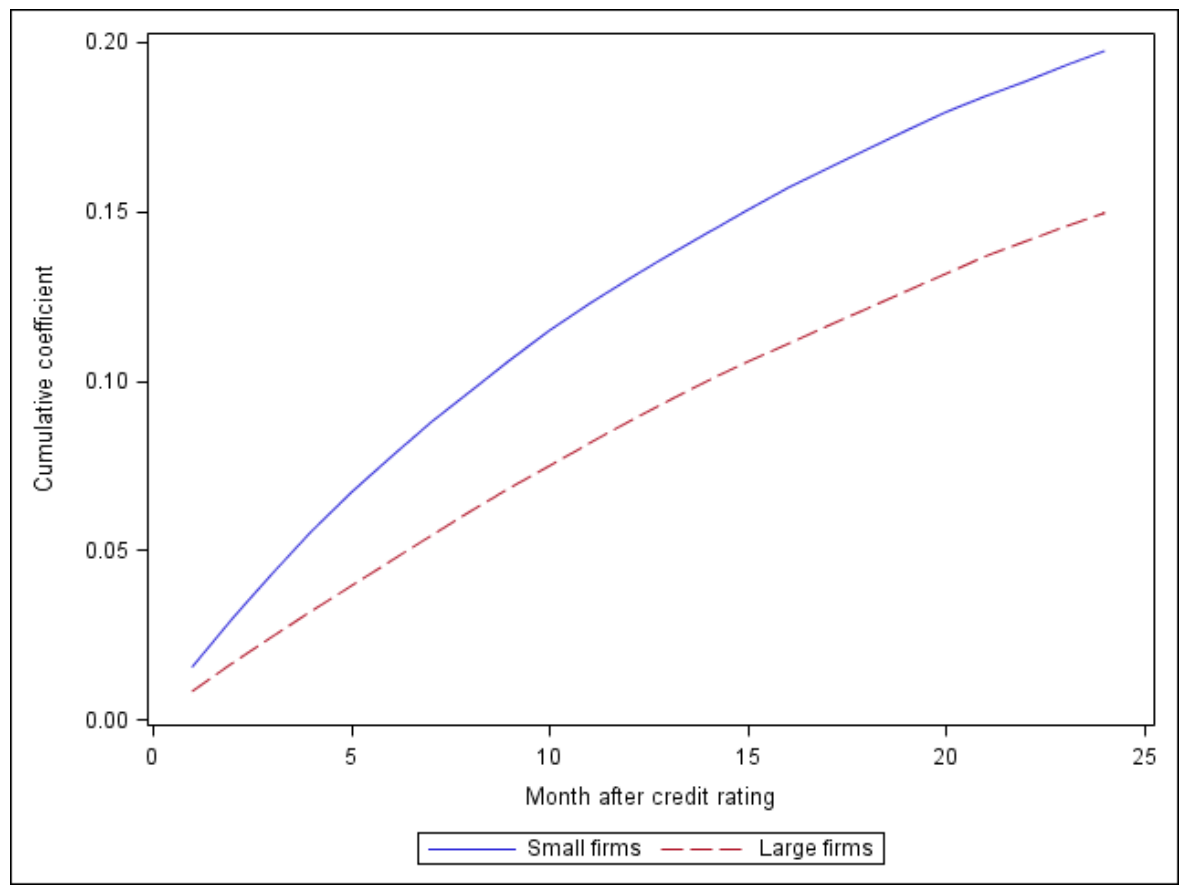

The figure presents summary statistics from regressions of the change in agency rating in future month $f(f=1,2, \ldots, 24)$ on the agency rating and the difference between the synthetic and agency ratings. Panels $\mathrm{A}, \mathrm{B}$ and $\mathrm{C}$ plot the coefficient on the difference variable. Panel D plots the cumulative coefficient on the difference. 